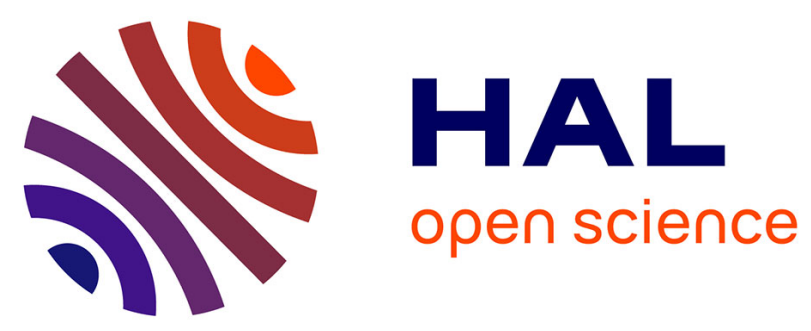

\title{
Crystal bending, subgrain boundary development, and recrystallization in orthopyroxene during granulite-facies deformation
}

\author{
Hugues Raimbourg, Toshihiro Kogure, Tsuyoshi Toyoshima
}

\section{To cite this version:}

Hugues Raimbourg, Toshihiro Kogure, Tsuyoshi Toyoshima. Crystal bending, subgrain boundary development, and recrystallization in orthopyroxene during granulite-facies deformation. Contributions to Mineralogy and Petrology, 2011, 162 (5), pp.1093-1111. 10.1007/s00410-011-0642-3 . insu00627836

\section{HAL Id: insu-00627836}

\section{https://hal-insu.archives-ouvertes.fr/insu-00627836}

Submitted on 29 Sep 2011

HAL is a multi-disciplinary open access archive for the deposit and dissemination of scientific research documents, whether they are published or not. The documents may come from teaching and research institutions in France or abroad, or from public or private research centers.
L'archive ouverte pluridisciplinaire HAL, est destinée au dépôt et à la diffusion de documents scientifiques de niveau recherche, publiés ou non, émanant des établissements d'enseignement et de recherche français ou étrangers, des laboratoires publics ou privés. 


\section{Crystal bending, subgrain boundaries development and recrystallization in orthopyroxene during granulite-facies deformation}

Hugues Raimbourg ${ }^{a}$, Toshihiro Kogure ${ }^{\mathrm{b}}$, Tsuyoshi Toyoshima ${ }^{\mathrm{c}}$

(a) University of Orléans, France/JAMSTEC, Yokosuka, Japan

(b) Department of Earth and Planetary Science, Graduate School of Science, The University of Tokyo, Japan

(c) Department of Geology, Faculty of Science, University of Niigata, Japan

Corresponding Author:

Hugues Raimbourg, ISTO, 1a rue de la Férollerie, 45071 Orléans, France

Tel: +33-3-30-02-18-82

Email: hugues.raimbourg@univ-orleans.fr

Keywords: Pyroxene, grain boundary, dislocations, recrystallization, TEM, EBSD 


\section{1-Abstract}

A prominent feature of a granulite-facies shear zone from the Hidaka Main Zone (Japan) is the folding of orthopyroxene (opx) porphyroclasts. Dislocation density estimated by Transmission Electron Microscope (TEM) and chemical etching in homogeneously folded domains is too low to account for the amplitude of crystallographic bending, leading us to propose a model similar to "flexural slip" folding, where folded layers are $\mu \mathrm{m}$-wide opx layers between thin planar clinopyroxene (cpx) exsolutions. Extension (compression) in the extrados (intrados) of the folded layer is accommodated by dislocations at the cpx-opx interfaces.

Alternatively to distributed deformation, crystal bending also localizes in grain boundaries (GB), mostly oriented close to the (001) plane and with various misorientation angles but misorientation axes consistently close to the $\boldsymbol{b}$-axis. For misorientation up to a few degrees, GBs were imaged as tilt walls composed of regularly spaced (100)[001] dislocations. For misorientation angles of $7^{\circ}$, individual dislocations are no longer visible, but high-resolution TEM (HRTEM) observation showed the partial continuity of opx tetrahedral chains through the boundary. For $21^{\circ}$ misorientation, the two adjacent crystals are completely separated by an incoherent boundary. In spite of these atomic-scale variations, all GBs share orientation and 
rotation axis, suggesting a continuous process of misorientation by symmetric incorporation of (100)[001] dislocations.

In addition to the dominant GBs perpendicular to the (100) plane, boundaries at low angle with (100) planes are also present, incorporating dislocations with a component of Burgers vector along the $\boldsymbol{a}$-axis. The two kinds of boundaries combine to delimit subgrains, which progressively rotate with respect to host grains around the $\boldsymbol{b}$-axis, eventually leading to recrystallization of large porphyroclasts.

\section{2-Introduction}

The interplay between deformation, grain size decrease and mechanical strength is a major process to account for the localization of the ductile deformation; deformation leads to dynamic recrystallization to a finer grain-size, which can cause a transition in deformation mechanisms and rock weakening, which, in turn, enhances deformation (e.g. Boullier and Gueguen (1975), Precigout, et al. (2007), Raimbourg, et al. (2008)). Though the microscopic mechanisms operative are not constant depending on strain rate and temperature (Hirth and Tullis 1992), grain size reduction involves the creation of a large surface of grain boundaries and is therefore ultimately controlled by GB structure and properties.

One possible mechanism for recrystallization is the evolution of subgrain boundaries 
into "true" GBs with progressive misorientation. The transition between subgrain -regular arrays of dislocations within a single crystal- and GBs -incoherent zone separating two distinct crystals- is often associated with a misorientation angle of $10-15^{\circ}$ (e.g. White (1977)), on the idea that for larger angles dislocations should be too closely spaced for coherent crystal to be present between them (Read 1953). On the other hand, high-resolution transmission electronic microscopy observations of the boundary core, for example in $\mathrm{ZnO}$ (Sato, et al. 2005) or in olivine (Heinemann, et al. 2005), revealed a structure made of dislocation-like units separating good crystal domains, with misorientations up to $\sim 20^{\circ}$. This "low-angle" model of the boundary in terms of alternating good crystal and dislocation-like structural units was extended theoretically up to $53.1^{\circ}$ of misorientation for [001] symmetrical boundaries in silicon (Levi, et al. 1991). Leaving apart these peculiar cases, where the boundary and the misorientation axis have particular crystallographic orientations, generally, high-angle GBs cannot be described like low-angle GBs only in terms of dislocations and other approaches need to be developed (see the review in Smith (1996)). Independently of the atomic-scale descriptions considered, high- and low-angle GB have different properties in terms of energy (Duyster and Stöckhert 2001), element segregation (Hiraga, et al. 2004) and diffusivity. Another key property with respect to recrystallization is GB 
mobility: There is an increase in the mobility of the GB with misorientation, although there is no clear-cut transition between low- and high-angle GBs(see the review in Drury and Pennock (2007)).

As most of the concepts and models on these topics are derived from works on metals, their applicability to silicates is not trivial, as special problems arise due to silicates' low symmetry and low number of slip systems with respect to metals. Deformation of opx is primarily achieved by the glide on (100)[001] slip system (Etheridge 1975; Poirier 1995; Steuten and Van Roermund 1989), far short of the five independent systems required for an arbitrary deformation geometry, but also insufficient to account for the development of subgrains, involved in models of recrystallization based on subgrain rotation (e.g. Guillopé and Poirier (1979)).

Deformation microstructure, such as crystal bending, subgrains and recrystallized grains, are extensively present in the mylonitic textures presented here and their boundaries have been exceptionally preserved from late-stage retrogression. Based on electron back-scattered diffraction (EBSD) and TEM observations, we propose in this study (i) to describe how the deformation of orthopyroxene prophyroclasts is accommodated within the crystal, including the development and progressive misorientation of GBs and (ii) to relate the properties of such intra-grain deformation structures with the whole 
process of recrystallization operative during mylonitization.

\section{3-Geological settings}

The mylonite studied here is located in the western border of the Hidaka Main Zone, a unit within Hidaka Metamorphic Belt interpreted as continental gabbros exhumed from the middle crust (Arita, et al. 1978; Jolivet and Miyashita 1985; Miyashita and Maeda 1978; Toyoshima, et al. 1994). The mylonite, constituted principally of elongated (up to a few $\mathrm{mm}$ ) orthopyroxene (opx) grains embedded in a matrix of small $(\sim 50 \mu \mathrm{m})$ plagioclase grains (details of the microstructure in Raimbourg, Toyoshima, Harima and Kimura (2008)), is characterized by a strong dextral deformation at granulite-facies conditions (T $\sim 800-900^{\circ} \mathrm{C}$ and $\mathrm{P} \sim 6.1-7.2 \mathrm{kbar}$ ) (Osanai, et al. 1991; Toyoshima, et al. 2000), which was completely preserved from lower-grade retrogression described in Kanagawa, et al. (2008).

\section{4-Internal structure of deformed opx grains}

\subsection{Grain-scale distribution of deformation}

As described in detail in Raimbourg, Toyoshima, Harima and Kimura (2008) and Toyoshima (1991), the major feature of deformed opx grains is their elongation in the simple shear strain field, accompanied by the acquisition of a strong crystallographic preferred orientation (CPO) with the (001) planes concentrated around the foliation 
plane and the $c$-axes around the lineation.

\subsubsection{Definitions}

On the basis of their geometry at atomic-scale, which is defined later (See section 4.2), we define as low-, medium- and high-angle GB (LAGB, MAGB, HAGB), a boundary where the misorientation is in the range $0-5^{\circ}, 5-15^{\circ},>15^{\circ}$, respectively. We differentiate recrystallized grains from subgrains as the former are completely independent grains while the latter preserve some connection, i.e. some elastic strain, with surrounding porphyroclast. In accordance with this definition, recrystallized grains (subgrains) are bordered by HAGB (LAGB/MAGB). Note that with this terminology a subgrain boundary is simply a particular type of GB.

\subsubsection{Exsolution of clinopyroxene lamellae during deformation}

Opx deformation is accompanied by the exsolution of a dense network of parallel lamellae, a feature absent in opx collected far from the mylonite. An energy dispersive X-ray spectrometer (EDS: JEOL JED-2200) in a TEM (JEOL JEM-2010UHR) unraveled a significant concentration of $\mathrm{Ca}$ within the lamellae. Crystallographic structure (Fig. Supp. Mat. 1) as well as this calcium content leads to interpret these lamellae as calcic clinopyroxene (cpx) exsolutions, similar to the larger, semi-coherent exsolutions we analyzed with electronic microprobe (Raimbourg, Toyoshima, Harima and Kimura 
2008). These lamellae share the (100) plane with opx (Fig. Supp. Mat. 1) and constitute therefore an easy way to track orientation and potential distorsion of opx lattice.

\subsubsection{Grain folding}

In addition to their elongation, some opx grains are deformed with a "fold"-like geometry, i.e. with opposite hinges within a single grain, in contrast to simple crystal bending. Concomitantly with the deformation of the grain shape, opx crystallographic lattice itself is folded, as evidenced by the curvature of the densely distributed lamellae. We carried out the characterization (axis and rotation angle) of such internal rotations using an electron-backscattered diffraction (EBSD) system (HKL, Channel 5) attached to an FE-SEM microscope (JEOL JSM-7000F).

Measurements at the points regularly spaced along the length of an opx with a curved shape (Fig. 1) show that the large internal rotations of the crystal structure are concentrated around the $\boldsymbol{b}$-axes, themselves near the Y axis of the deformation ellipsoid, while the $\boldsymbol{a}$ - and $\boldsymbol{c}$-axes are much more scattered within girdles. At most, between points 8 and 31 , the internal rotation angle reaches as much as $40^{\circ}$, while the rotation axis lies very close to the $\boldsymbol{b}$-axis.

A fraction of the crystal rotation in Fig. 1 can be accounted for by several GBs, underlined by sharp orientation contrast in the fore-scatterred image (Fig. 1A), while 
elsewhere in the grain the rotation is more gradual, without visible contrast. To further unravel the grain internal microstructures, we carried out the chemical etching of polished surfaces, following the method described in Wegner and Christie (1985), which resulted in the preferential dissolution of (i) cpx lamellae parallel to the opx (100) planes and (ii) GBs, which appear as thin black lines (Fig. 2). Please note that the etched surfaces, as well as thin sections described throughout this manuscript, are prepared in the $\mathrm{XZ}$ deformation plane, i.e. opx are cut in average close to their (010) plane.

Chemically etched sections confirmed the two concurrent modes of crystal bending, either homogeneous lattice distorsion, without visible boundary (Fig. 2C), or heterogeneous lattice distorsion (Fig. 2A and B), where crystal distorsion is concentrated in boundaries.

\subsubsection{Homogeneous folding}

In homogeneous folding, the progressive rotation of the lattice is homogeneously distributed through the folded domain. Discontinuities in crystal orientation, i.e. GBs, are absent, as evidenced by the fore-scattered image (Fig. 3A) and EBSD map (Fig. 3B). This smooth bending is confirmed by the profile XY (Fig. 3D), where the crystal, with respect to reference point $\mathrm{X}$, is progressively misorientated along the fold, by rotation about the $\boldsymbol{b}$-axis (Fig. 3C). 


\subsubsection{Heterogeneous folding and formation of GBs}

In contrast to homogeneous folding, many bent areas show sharp discontinuities in crystal orientation, revealed either by fore-scattered images and EBSD (Fig. 1 and 4) or by chemical etching (Fig. 2A and B). The precision to be expected in the automatic mapping and detection of boundary by EBSD, which can be estimated in Fig. 3D from the scatter of the points around a smooth trend of increasing misorientation, is of the order of $1^{\circ}$. In contrast, etching made boundaries with misorientation as low as $0.2^{\circ}$ degrees apparent (e.g. Fig. 2A) and constitutes therefore a finer tool to analyze grain internal structures.

Most of the GBs are straight and at large angle to the traces of opx (100) planes (Fig. 2A). The other kind of GB, less abundant, appear in etched surfaces as tortuous lines, at low angle to the traces of opx (100) planes (Fig. 2B). Finally, GBs with a structure intermediate between these 2 endmember geometries are rare.

\subsubsection{Recrystallization}

In some opx porphyroclasts, we observed also aggregates of subgrains/grains, localized on porphyroclasts rims or in cross-cutting deformation bands. The grains have a size from a few to a few tens of microns, misoriented around $\boldsymbol{b}$-axis with respect to surrounding opx domains (Fig. 4A), with misorientation from a few degrees up to 
$30-40^{\circ}$. Their boundaries can be interpreted as an array of the two kinds of boundaries described above. In rare examples, the grain aggregates within an opx porphyroclast do not follow the same simple geometrical pattern (Fig. 4B) and seem to be randomly misoriented with respect to host grain. In such cases, grains are larger and devoid of cpx exsolutions.

In a final stage of deformation, these small grains get separated by on-going deformation from parent opx porphyroclasts to form asymetric tails (Raimbourg, Toyoshima, Harima and Kimura 2008). The crystallographic fabrics of these grains is random, as a result of deformation by a grain-size-sensitive deformation mechanism.

\subsection{Microstructure and low-angle grain boundaries at atomic-scale}

We carried out the atomic-scale observations of the deformation microstructures described above using a TEM (JEOL JEM-2010UHR) operated at 200kV on ultra-thin sections prepared from etched samples by focused ion beam (FIB: HITACHI FB-2100). To image structures misoriented about the opx $\boldsymbol{b}$-axis and as high-resolution TEM (HRTEM) imaging requires to align the incident electron beam along the crystallographic zone axis of low index, most sections were prepared perpendicular to the $\boldsymbol{b}$-axis.

\subsubsection{Lamellae}


In all these ultra-thin sections, lamellae with an orientation parallel to (100) planes are present (Fig. Supp. Mat. 1). Their thickness is variable, with typical values of the order of tens to hundred $\AA$, while their length is in most cases larger than $10 \mu \mathrm{m}$. They are irregularly distributed, with an average spacing of the order of $1 \mu \mathrm{m}$. Some of these lamellae concentrate dislocations on their surfaces, with a density often larger than surrounding opx domains.

\subsubsection{Distributed dislocations}

In spite of the large crystal distorsion unveiled by EBSD, in most ultrathin sections dislocations ditributed in the bulk of opx are surprisingly rare, which is in agreement with the relative lack of etch pits in opx compared to hosted inclusions (ilmenite or cpx). They were found to be most abundant in homogeneously folded portions of the porphyroclasts (See 5.3), reaching concentrations of $\sim 10^{12} \mathrm{~m}^{-2}$.

\subsubsection{Straight LAGBs}

Straight LAGBs are systematically oriented, in etched sections, close to the perpendicular to the traces of the opx (100) planes. Misorientation axis between adjacent domains is close to opx $\boldsymbol{b}$-axis, though for very low misorientation angle $\left(<0.5^{\circ}\right)$ it was difficult to be determined precisely. As seen in TEM images, these boundaries, for low misorientation angle $\left(<2-3^{\circ}\right)$, are composed of regularly spaced 
dislocations, which appear strongly when $h 0 l$ (small $h$ index and $l= \pm 2, \pm 4, .$. ) reflections are excited (Fig. 5A) and almost disappear when $h 00$ reflections are excited (fig. 5B). The contrast conditions, the geometry of the boundary as well as the misorientation axis are all fully consistent with the interpretation of these LAGB as tilt walls made of (100)[001] dislocations.

Dislocation spacing (d) decreases with the misorientation angle $\theta$ (Fig. 6), following a relationship close to the theoretical value for dislocation tilt walls (Hirth and Lothe 1968):

$$
\mathrm{d} \approx \frac{\mathrm{B}}{\theta} \quad(\text { Eq. } 1)
$$

where $\mathrm{B}$, the length of the Burgers vector, was taken as unit cell parameter $\mathrm{c} \approx 5.24 \AA$ (Van Duysen, et al. 1985).

At higher resolution, these dislocations are slightly dissociated into two partials along the (001) plane (Fig. 7). In a thin domain, parallel to (100) plane, which includes and slightly extends over the partials, opx lattice periodicity is divided by two, as the result of ortho- to clino-enstatite transformation (Buseck and Iijima 1974).

4.2.4 Curved low angle grain boundaries

Another type of LAGB is constituted of tortuous boundaries at low angle to the traces of opx (100) planes. TEM imaging of these curved GB, with a misorientation of $\sim 2^{\circ}$ 
principally around $\boldsymbol{b}$-axis, showed that they are composed of dislocations, similarly to the straight LAGB (Fig. 8). The orientation of the GB is not constant; even at this very small scale, the boundary has a zigzag structure made of a succession of segments either perpendicular or at low angle to (100) planes. Portions at low angle to (100) planes have irregular features: the orientations of the dislocation lines as well as of the boundary itself vary (Fig. 8 (D) and (E)), strain patterns are often irregular, in contrast with the portions perpendicular to (100) planes (C). Our attempts (extinction of the dislocations or HRTEM imaging) to rigorously constrain the Burgers vector of the dislocations involved in boundaries at low angle to (100) planes were unsuccessful.

\subsection{Evolution of GB structure with increasing misorientation}

Although we could observe several kinds of GB in opx porphyroclasts, the straight ones perpendicular to opx (100) planes are by large the most abundant and have the simplest structure, so that they constitute an ideal target to study the evolution of the boundary with increasing misorientation.

\subsubsection{Presence of dislocations and elastic strain}

While in Fig. 5, where misorientation is $\sim 0.5^{\circ}$, dislocations appear as black strain dots separating domains of the boundary where the lattice is less strained, in Fig. 8 (C), where misorientation is $\sim 1.5^{\circ}$, i.e. three times larger, strain fringes cover the whole 
boundary.

Higher misorientations, of the order of 5-15 , yield, for (100)[001] dislocations organized into tilt walls, theoretical spacing of the order of 3-1 $a$ (Eq. 1). In such case, where calculated dislocation spacing is roughly equivalent to lattice cell parameters, the description of the boundary in terms of dislocations does probably not hold (Read 1953).

In contrast with LAGB (fig. 5), MAGB (Fig. 9) and HAGB (Fig. 10 and 11) do not appear an alignement of strain dots between continuous opx, but as a line separating two distinct opx domains. Some of the cpx exsolution lamellae end on the boundary, while some of them are continuous through it. When the $h 0 l$ reflections with low $h$ indices are excited, regularly spaced strain zones are apparent on GB with $7^{\circ}$ (Fig. 9) and $11^{\circ}$ (Fig. 10) of misorientation, while we could not observe any strain contrast near the GB with $21^{\circ}$ of misorientation, whatever the diffraction conditions.

\subsubsection{Atomic structures}

In the $7^{\circ}$-misoriented LAGB (Fig. 9), the atomic scale structure of the boundary is well imaged especially with 400 lattice fringes (Fig. 9B), where every fourth fringe has a brighter contrast (probably because of a slight misorientation of the incident beam from the exact [010] direction). These lattice fringes correspond to the repetition of four units 
(a plane for single tetrahedral chains and a plane for octahedral slabs) within each lattice cell in the $\boldsymbol{a}$-direction. The boundary varies between domains where the crystal on both sides is not connected, and domains where the fringes are continuous through the boundary. The nano-scale strain patterns associated (not to be confused with micron-scale ones seen with TEM in Fig. 9A), have a pseudo-periodic spacing roughly equivalent to dislocation spacing in the dislocation tilt wall model. At the sub-lattice scale, some 400 lattice fringes are continuous and some are not, which must correspond to the fact that some tetrahedral chains and octahedral slabs are continuous and some are broken, a structure that cannot be expressed by conventional dislocation scheme.

For $11^{\circ}$ of misorientation, i.e. at the MAGB/ HAGB transition, although micron-scale strain is visible when $h 0 l$ reflections are excited and disappear for $h 00$ excitation(Fig. 10), HRTEM images are equivocal as to the continuity of (100) planes through the boundary. Finally, for HAGB (misorientation $\sim 21^{\circ}$ ), no micron-scale strain is visible and the boundary appears in HRTEM as a band of width $1 \mathrm{~nm}$ or less made of bright, incoherent material (Fig. 11).

\subsubsection{Three-dimensional geometry of the boundary}

The macroscopic, geometrical features of the GB oriented close to the perpendicular to the traces of opx (100) planes seem to be independent of the misorientation: They are 
relatively straight and the misorientation axis is close to opx $\boldsymbol{b}$-axis (e.g. Fig. 11C).

As regards the boundary geometry, all our observations, restricted to a plane of section, are insufficient to fully constrain it. Nevertheless, knowing the crystallographic orientation of both sides of the boundary, we can determine what orientation, in the plane of section, would have a theoretical boundary bissector (100) planes (similar to a tilt wall boundary made of (100)[001] dislocations) and compare it to the actual boundary. Irespective of the misorientation angle, GB trace are systematically oriented close to the trace of the plane bissector to (100) planes from the two adjacent opx domains (Fig. 12).

In conclusion, the geometry of the GB is constant and independent of its atomic-scale structure, which varies from coherent to incoherent with increasing misorientation.

\section{5-Discussion}

\subsection{Active slip systems in opx}

Although the clino- to orthoenstatite transformation has been proposed as a deformation process in opx (Coe and Kirby 1975; Coe and Müller 1973; McLaren and Etheridge 1976; Raleigh, et al. 1971), the paucity of clino-enstatite lamellae observed in our samples (mostly related to the dissociation of (100)[001] dislocations into two partials, see Fig. 7) as well as the very large elongation (shape ratio correspond to finite shear 
strain $\gamma$ locally up to more than 20), imply that most of the deformation results from dislocation activity.

The dislocation system involved in plastic deformation is principally (100)[001], as evidenced by (i) the porphyroclast CPO, (ii) the GB geometry and misorientation axis and (iii) the direct characterization by TEM of the nature of the dislocations involved in GB. This slip system is the most common one in opx, both from natural and experimental samples (Kohlstedt and Van der Sande 1973; Naze, et al. 1987; Van Duysen, Doukhan and Doukhan 1985). Several other minor systems are described by these authors, which have as Burgers vector either $\boldsymbol{b}$ or $\boldsymbol{c}$. Steuten and Van Roermund (1989) noted that none of these slip systems can account for the development of GBs parallel to (100) planes. We face in our study the same question, as the dislocations present in the boundary parallel to (100) planes and which accommodate a rotation around $\boldsymbol{b}$ (Fig. 8) have by construction, as Burgers vector, the $\boldsymbol{a}$-axis (Hirth and Lothe 1968). The spacing between the elastic strain concentrations observed in these boundaries (Fig. 6 and 8E) is also in agreement with the $\boldsymbol{a}$-axis as Burgers vector.

On the other hand, the detailed structure of the boundary parallel to (100) planes appears much more complex than this simple model (Fig. 8C to E), as the boundary is not straight and perfectly symetric with respect to adjacent opx domains and the strain 
concentrations are irregularly distributed along the boundary. The lattice parameter $a$ is much larger ( 18.2 $\AA$ (Van Duysen, Doukhan and Doukhan 1985)) than $b$ or $c$, so that the energy of dislocations with the $\boldsymbol{a}$-axis as Burgers vector is probably quite high and such dislocations are unfavoured. Furthermore, as four silicate chains are superposed in the $\boldsymbol{a}$ direction within a unit cell, one may suppose that these chains terminate at different points within the boundary and that the associated dislocation is dissociated.

In spite of the complexity of the boundary parallel or at low angle to $\boldsymbol{a}$-planes, it is unambiguously made of dislocations, which implies the activation, in addition to the dominant (100)[001], of another slip system, whose Burgers vector, if not simply $\boldsymbol{a}$, has some component along the $\boldsymbol{a}$-axis. Such dislocations, which are not observed elsewhere in the crystal nor reported elsewhere, may be activated in very specific cases where they are geometrically necessary, for example in segments of GB joining tilt walls made of (100)[001] dislocations. In materials such as silicates, the low number of easy slip system may lead, because of locally high stresses, to the activation of less-favoured systems.

\subsection{Homogeneous lattice folding}

\subsubsection{Geometrically necessary dislocations}

From the theory of bending of plates (Timoshenko and Goodier 1951), if the opx lattice 
curvature was purely elastic, the magnitude of stresses $\sigma$ acting to bend the crystal would be of the order of $\sigma \sim \frac{E t}{R}$, with E the Young's modulus $(\sim 100$ GPa (Duffy and Vaughan 1988)), $t$ the thickness of the folded layer and $\mathrm{R}$ the curvature of the folded section. Taking the example in Fig. $1, \mathrm{t} \sim 100 \mu \mathrm{m}, \mathrm{R} \sim 2000 \mu \mathrm{m}$, therefore $\sigma \sim \frac{\mathrm{E}}{20}$, i.e. of the order of a few GPa, which is by orders larger than what is recorded in ductilely deformed rocks. This implies that lattice curvature is accommodated plastically by the presence of edge dislocations of a given sign (Hirth and Lothe 1968), namely the (100)[001] dislocations in our case. The density $\rho$ of these geometrically necessary dislocations can be related to their Burgers vector (in this case unit cell $\boldsymbol{c}$ ) and to the curvature $\frac{1}{\mathrm{R}}$ of the lattice along the fold as (Nicolas and Poirier 1976):

$$
\left.\rho=\frac{1}{\mathrm{cR}} \quad \text { (Eq. } 2\right)
$$

Considering the example of the opx homogeneously bent in Fig. 13, lattice curvature radius is of the order of $\mathrm{R}=700 \mu \mathrm{m}$, yielding, for a Burgers vector of length $\mathrm{c} \approx 5.24 \AA$, (Van Duysen, Doukhan and Doukhan 1985)), a theoretical dislocation density of $2.7 / \mu \mathrm{m}^{2}$. Actual dislocation density, calculated on the TEM micrograph by counting dislocations away from cpx lamellae (Fig. 13C) or on the SEM image by counting triangular etch pits away from lamellae (Fig. 13B), is in the range $1-1.2 / \mu \mathrm{m}^{2}$, i.e. roughly half of the theoretical density. 
One can wonder whether our low dislocation density is not the result of repeated unfortunate sampling, where we would have missed dislocation tilt walls concentrating the curvature outside of the zones we analyzed by TEM or SEM. Our "limit of detection" of tilt walls corresponds to misorientation of $\sim 0.2^{\circ}$, above which they are unraveled by etch pit as thin black lines. Assuming that all the curvature is accommodated by $0.2^{\circ}$ misorientation tilt walls, the radius of curvature $\mathrm{R}=700 \mu \mathrm{m}$ implies that these walls should be spaced by $2.4 \mu \mathrm{m}$, i.e. there should be several of them visible in the TEM ultrathin section, whose width is $\sim 10 \mu \mathrm{m}$. As this is not the case, lattice curvature has to be accommodated homogeneously, i.e. by dislocations distributed more or less evenly in the volume.

\subsubsection{Model of "flexural slip" folding}

While the actual density of dislocations in opx bulk is too low to explain the lattice curvature, HRTEM images unveiled the presence, at the interface between folded cpx lamellae and opx layers, of densely distributed dislocations (Fig. 14).

To understand the role of these dislocations in folding, let us assume that opx is not folded as a thick monolayer but as a stack of $\mu \mathrm{m}$-thick layers, separated by cpx exsolution lamellae (Fig. 15A). Let us further suppose that these lamellae can accommodate differential displacement, similarly to macroscopic models of "flexural 
slip folding" (Ramsay 1967). If the folding was purely elastic, then for a layer of thickness $\mathrm{t}$, curved with a radius $\mathrm{R}$, a given length 1 (in unstressed state) parallel to $\boldsymbol{c}$-direction along the extrados (intrados) of the layer is stretched (shortened) to a length $\mathrm{l}\left(1+\frac{\mathrm{t}}{2 \mathrm{R}}\right)\left(\mathrm{l}\left(1-\frac{\mathrm{t}}{2 \mathrm{R}}\right)\right)$. In reality, this deformation is not elastic and we suppose that it is accommodated by regularly spaced dislocations on opx layers interfaces (i.e. along cpx lamellae), which account for the difference in (001) plane density between two adjacent layers (Fig. 15C).

The difference in displacement between upper and lower surfaces is:

$$
l\left(1+\frac{t}{2 R}\right)-l\left(1-\frac{t}{2 R}\right)=l \frac{t}{R}
$$

If this difference is taken equal to the distance between (001) planes (i.e. $d_{001}$ ), mismatch between upper surface of the lower layer and lower surface of the upper layer is equivalent to inserting an extra $c$-plane on one side of the boundary, i.e. an edge dislocation on the boundary (Fig. 15C). On layer interface, the spacing 1 between dislocations accommodating difference in $\boldsymbol{c}$-plane density is thus:

$$
\mathrm{l} \frac{\mathrm{t}}{\mathrm{R}}=\mathrm{c} \rightarrow \mathrm{l}=\frac{\mathrm{Rc}}{\mathrm{t}}
$$

The dislocation density associated with this distribution is finally given by:

$$
\rho=\frac{1}{\mathrm{lt}}=\frac{1}{\mathrm{Rc}}
$$

i.e. the density is the same as Eq.2, which was calculated for homogeneously distributed 
dislocations.

"Flexural slip" folding and concentration of dislocations on opx layer interfaces (i.e. parallel to (100) planes) constitutes therefore another possible distribution of dislocations to accommodate lattice curvature, alternative to either (i) dislocations homogeneously distributed in the bulk or (ii) dislocations organized into tilt walls (i.e. parallel to (001) planes). On the example of Fig. 13, it accounts for about half of the curvature. The occurrence of flexural "flexural slip" folding requires the presence of decoupling interfaces. This role is played by exsolutions, but not in the sense that there is actually slip along the lamellae, but rather in the sense that exsolution process itself, through the growth of the lamellae, enables the opx on both sides of the lamellae to move with respect to each other, similarly to the way synkinematic veins accommodate differential displacement of their rims (Passchier and Trouw 1996).

\subsubsection{Nature and role of the dislocations at cpx-opx interfaces}

Van Duysen, Doukhan and Doukhan (1985) interpreted these dislocations (Fig. 14) as thermal mismatch dislocations, emplaced as a result of the difference in $d_{001}$ between cpx and opx at temperature of the deformation $\left(\sim 800^{\circ} \mathrm{C}\right)$ and subsequently preserved throughout cooling. The model of flexural slip we propose above (Fig. 15A) leads to an alternate explanation, where these dislocations accommodate the lattice curvature (Fig. 
Supp. Mat. 3).

Dislocation spacing cannot be directly estimated using Van Duysen, Doukhan and Doukhan (1985)'s results because of a mistake in opx thermal expansion coefficient. After correction and integration of the effect of pressure (See Appendix), mismatch dislocation spacing is of the order of a few hundreds of nanometers, with further precision impossible because of uncertainty in crystallographic parameters.

In the "flexural slip" folding model, on the other hand, with $\mathrm{R} \sim 1 \mathrm{~mm}, \mathrm{t} \sim 1-5 \mu \mathrm{m}$ (Fig. 13), the dislocation spacing predicted by Eq.3 is in the range 100-500nm. Actual average spacing of dislocations at cpx-opx interfaces (Fig. 14) is in good agreement with values from both models.

One can nevertheless note that the dislocation density is highly variable along a given lamellae and even varies between its upper and lower surface (Fig. 14). Such features are not accounted for by the simple crystallographic thermal mismatch model by Van Duysen, Doukhan and Doukhan (1985). On the contrary, in the flexural slip model, the density of dislocation may vary along a lamellae, as a result of variations in curvature. Furthermore, in Fig. 15, we considered the whole cpx lamellae as concentrating the relative slip and the dislocation, irrespective of its lower/upper surface. In reality, depending on how the exsolution proceeds and on which side the lamellae grows, the 
density of the dislocations on the lamellae upper and lower surfaces may be different (Fig. Supp. Mat. 3). As a consequence, the heterogeneous dislocation distribution at cpx-opx interfaces can only be accounted for when considering our folding model, where dislocations are geometrically necessary to accommodate lattice curvature. On the other hand, one should note that the two models (thermal mismatch and mechanical folding) are not mutually incompatible and the actual distribution of dislocations probably reflects the combination of both processes (Fig. Supp. Mat. 3).

\subsubsection{Energy budget in flexural slip folding}

The total energy stored in the crystal when dislocations are arranged according to "flexural slip" model is difficult to compute. On the other hand, one can qualitatively estimate the variations in energy when, within the model framework, the density of decoupling interfaces diminishes/layer thickness increases.

To estimate energy budget, let us take as example the case where the thickness of opx layer is $5 \mu \mathrm{m}$, the curvature radius $1 \mathrm{~mm}$, Eq. 3 predicts that dislocation spacing is $\approx 100 \mathrm{~nm}$ along the cpx lamellae. In contrast, the distance between dislocations in two adjacent lamellae is of the order of opx layer thickness, $5 \mu \mathrm{m}$, i.e. 50 times farther than neighboring dislocations on the same lamellae. As elastic stresses associated with dislocations scale as $\mathrm{r}^{-1}$ (Hirth and Lothe 1968), where $r$ is the distance to the 
dislocation core, one can neglect, in the energy of the dislocation distribution, the interaction energy between adjacent layers. The interaction energy is thus principally the result of parallel (100)[001] dislocations located on a common (100) plane. Let us consider two neighboring dislocations on (100) plane. Their energy of interaction W per unit length $\mathrm{L}$ is given by:

$$
\frac{\mathrm{W}}{\mathrm{L}}=-\frac{\mu}{2 \pi(1-v)} c^{2} \ln \frac{\mathrm{r}}{\mathrm{r}_{\alpha}}
$$

Where $\mu, v, c, r_{\alpha}$ are respectively the shear modulus, Poisson ration, unit cell parameter and a constant for the logarithmic argument to be dimensionless (Hirth and Lothe, Eq-5.17 (1968)). This energy increases as r, in other words dislocation spacing 1 in Eq.3, decreases. The total energy of a unit volume of folded pyroxene is, when considering only the interaction energy of neighboring dislocations on (100) plane, porportional to $\mathrm{W} \rho$, where $\rho$ is the dislocation density of Eq.2.

Let us finally compare two configurations of flexural folding, the first one where there are few, thick opx lamellae and the other one where there are many, thin opx lamellae. Dislocation spacing 1 is inversely proportional to the thickness of opx lamellae, hence $\mathrm{W}$ increases as thickness increases. On the other hand, dislocation density is constant, irrespective of the opx layer thickness. As a result, the volumic energy of folded opx decreases as the thickness of the folded layers decreases. The case is much similar to the 
elastic case, where the stresses necessary to bend a layer scale as $\sigma \sim \frac{\mathrm{Et}}{\mathrm{R}}$, i.e. $\sigma$ decreases as the layer thickness decreases. In terms of energy, it is easier to bend plastically or elastically a multilayer assemblage made of numerous, thin layers than few, thick layers. As thickness is inversely proportional to the density of decoupling surfaces, hence on density of cpx exsolutions, "flexural slip" folding energy is controlled by the process of exsolution.

\subsection{Subgrain/grain transition}

While there is some regularly spaced elastic strain on the GB with $11^{\circ}$ misorientation shown in Fig. 10, other GB we analyzed had a similar misorientation but no elastic strain. The transition between MAGB and HAGB, i.e. between subgrain and recrystallized grains, occurs therefore probably for misorientation in the range $10-15^{\circ}$. $10^{\circ}$ corresponds to a critical dislocation spacing estimated as $\mathrm{d}_{\text {crit }} \approx \frac{c}{\theta_{\text {crit }}} \approx 30 \mathrm{~nm} \approx$ $1.6|\boldsymbol{a}|$, i.e. for dislocations spacing smaller than 1.5 times the lattice parameter in the direction of the boundary where dislocations pile up, lattice distortions in the boundary become too large for the two adjacent crystals to remain connected.

In olivine, Heinemann, Wirth, Gottschalk and Dresen (2005) observed GB made of regularly spaced dislocations for tilt angles up to $21.5^{\circ}$, which correspond to a spacing $\mathrm{d}_{\text {crit }}=\frac{c}{\theta_{\text {crit }}} \approx 16 \mathrm{~nm} \approx 1.6|\boldsymbol{b}|$, where $\boldsymbol{b}$ is the cell dimension along the dislocation 
array (equivalent to $\boldsymbol{a}$ in the opx tilt walls). Therefore, the large difference of transition between low- and high-angle grain boundary structure between olivine and pyroxene might be explained in terms of critical spacing of dislocations in the boundary.

In the transitional domain of MAGB, where lattices are connected through the boundary but dislocations are too densely distributed to be individualized, we observed periodic strain along the boundary, with a spacing $~ 150 \mathrm{~nm}$ (Fig. 9), i.e. much larger than spacing calculated from theoretical law. Such long-range periodic strain pattern was also observed in olivine GB with large misorientation by Heinemann, Wirth, Gottschalk and Dresen (2005), who related its periodicity to the coincidence, on the GB, of lattice sites from both crystals.

\subsection{Models of recrystallization}

Any model invoked to account for recrystallization involves at some point the increase in GB surface with respect to original, undeformed grain. The two mechanisms of crystal folding described here have contrasted effects on recrystallization: Homogeneous folding (4.1.4) does not lead to GB growth, on the contrary to the localized accommodation of bending, resulting in organization of dislocations into tilt walls and further evolution into GBs (4.1.5). Consequently, bending is a factor of recrystallization only if deformation is heterogeneous at the grain scale. Our 
observations do not provide a clear pattern as to which factors controls whether bending is homogeneous or heterogeneous. Nevertheless, on the basis of the energy analysis in 5.4, homogeneous folding is favoured when the thickness of folded opx layers is small, i.e. when exsolutions are densely distributed. The process of cpx exsolution is therefore potentially controlling the style of folding in elongated opx porphyroclasts, hence its potential for recrystallization.

Considering the cases where GB develop in response to folding, two distinct mechanisms may lead to recrystallization: Migration of grain boundaries from low- to high-density of dislocations domains (Sellars 1978; Tullis and Yund 1985) or dislocation climb and organization into tilt walls and formation of subgrains (Guillopé and Poirier 1979). Hirth and Tullis (1992) describe for example in quartz several regime of dislocation creep, based on different combination of these two possible mecanisms for restoration. For opx, data is limited to Etheridge (1975)'s analysis of recrystallization as the result of the migration of high-angle grain boundaries, generated in "kink bands" domains, which are similar to the GB at large angle to (100) planes traces that are described here.

\subsubsection{Subgrain rotation-recrystallization}

As already proposed, on the basis of $\mathrm{CPO}$, in Raimbourg, Toyoshima, Harima and 
Kimura (2008), all the characteristics of the GBs we described here (geometries and atomic scale structure of the LAGB, misorientation axes) point to the major role played by (100)[001] slip system and associated rotation in subgrain formation. The subgrain $\rightarrow$ grain evolution is a bit more problematic: As described in halite by Drury and Pennock (2007) and Pennock (2005), the model of recrystallization where all subgrains rotate progressively with strain, eventually reaching a misorientation large enough for them to become independent grains may be oversimplified, as these authors described several kind of subgrains, of which only certain ones evolve into recrystallized grains with increasing strain. In this analysis, among the low-angle GB formed during deformation, Drury and Pennock (2007) makes the distinction between incidental and geometrically necessary boundaries (Kuhlmann-Wilsdorf and Hansen 1991), only the latter evolving potentially into high-angle GB separating recrystallized grains.

As shown by their CPO (Raimbourg, Toyoshima, Harima and Kimura 2008), elongated opx porphyroclasts are in average oriented so that the $c$ axes are close to elongation axis $\mathrm{X}$ and (100) planes close to the foliation plane XY. As a result, slip on the dominant (100)[001] slip system allows only further elongation parallel to X. The GBs parallel to (001) planes, also made of (100)[001] dislocation, combine to fold the whole grain, 
hence they enable shortening parallel to $\boldsymbol{c}$-axis, a mode of deformation which is not possible simply by slip. In that respect, these GBs can be considered as geometrically necessary, in the sense that they are controlled at large scale, by the deformation field of the grain and its surroundings. Similarly, as they accommodate the crystal rotations around the $\boldsymbol{b}$-axis induced by the GBs parallel to (001) planes, GBs parallel to (100) planes can be also considered as geometrically necessary, which can explain the activation of slip systems whose Burgers vector has a component along $\boldsymbol{a}$-axis, not reported so far in deformed opx and probably not an "easy" slip system. Furthermore, EBSD patterns of recrystallized grains (Fig. 5 of (Raimbourg, Toyoshima, Harima and Kimura 2008)), show that all grains are derived from parent grain by rotation only in a single direction (counterclockwise in the present case), which means that these rotations are not incidental but are kinematically necessary, i.e. they accomodate much larger-scale (e.g. porphyroclast scale) deformation. The corollary of this property is that rotations are expected to increase with strain, resulting in the evolution of subgrains into recrystallized grains. A large fraction of recrystallization in opx seems therefore to be related to localized bending within large porphyroclasts.

\subsubsection{Grain boundary migration}

Extensive migration of HAGB is not supported by their geometry: Although they are 
incoherent, most of them preserve the geometry of low angle GB, i.e. boundary plane is bissector of (100) planes of opx domains and rotation is about opx $\boldsymbol{b}$-axis (e.g. Fig. 11, 12 and 4 (A)). This implies that they grow from the incorporation of (100)[001] dislocations and that their mobility, if they have some, is restricted to the $c$ direction.

The major obstacle to GB movement, is the presence of coherent cpx exsolutions along the boundary, which pin it and hinder its mobility (e.g. Herwegh and Kunze (2002)). A contrario, in recrystallized zones, where most grains are exsolution-free, GB are likely to be more mobile, which could explain the transition between recrystallization patterns shown in Fig. 4: When exsolution lamellae still densely distributed (A), boundaries grow symmetrically by the addition of (100)[001] dislocations and misorientation axes are consistently close to $\boldsymbol{b}$-axis. In wider recrystallized domains (B), where exsolution lamellae have been expelled, the misorientation axes seem to be randomly distributed, which could be interpreted as the result of combined (i) migration of GB and (ii) potential activation of additional slip systems.

It seems therefore that the GB mobility, irrespectively of the misorientation angle, is primarily controlled by the density of exsolution present within opx lattice. The process of expulsion of cpx lamellae from opx is not clear, although it can be unequivocally associated with deformation (Fig. Supp. Mat. 2), as recrystallized grains have a much 
fewer exsolutions (Etheridge 1975; Raimbourg, Toyoshima, Harima and Kimura 2008).

The reequilibration of opx, over several microns, by Ca loss, near boundaries of recrystallized grains also supports a relatively high mobility of $\mathrm{Ca}$ in opx. This contrasts sharply with Skemer and Karato (2007)'s observation of grain growth inhibition: Calcium, because of its low mobility, is segregated near the GBs and prevents their migration. One may tentatively relate this difference to the static vs dynamic character of the microstructure: In Skemer and Karato (2007)'s static grain growth experiment, only element diffusion is involved, while the Ca-distribution shown in Fig. Supp. Mat. 2 is the result of deformation-assisted diffusion, which may greatly enhance Ca mobility. As a result, grain boundary migration is possible, but only in a late stage of porphyroclast disruption. Recrystallization in opx is therefore a multi-staged process, dominated by subgrain rotation recrystallization but where GB migration is eventually activated after expulsion of cpx lamellae.

\section{6-Conclusion}

The plastic deformation of opx porphyroclasts of the Hidaka mylonite zone led, in addition to strong grain elongation and $\mathrm{CPO}$ acquisition, to extensive intra-grain deformation, which manifests as lattice folding about $\boldsymbol{b}$-axis as a result of the presence of (100)[001] dislocations. This deformation is accommodated either homogeneously 
through the grain or by the formation of boundaries concentrating the misorientation. In the former case, dislocations distributed in the bulk opx are too few for the lattice curvature. To account for the discepancy, we developed a model similar to flexural slip folding, where opx layers, folded between cpx exsolutions, are able to slip with respect to each other, which results in the dense distribution of dislocations along the slip interfaces, i.e. along cpx lamellae surfaces. In the alternative mode of deformation, where curvature is accommodated by the formation of boundaries, we observed a transition between subgrain (connected crystals through the boundary) and recrystallized grain (disconnected crystals) around $10-15^{\circ}$. In addition, while for LAGB, individual dislocations are apparent, for MAGB, though elastic strain patterns are visible, the boundary appears as a continuous, thin frontier and individual dislocations are no longer visible. The connection of the crystals on the two sides of the boundary is only apparent at atomic-scale, as some lattice fringes are continuous through the boundary. Finally, as recrystallization is the result of the formation of subgrains and their progressive misorientation, the two modes of grain folding (homogeneous/heterogeneous) have a great impact on the potential to recrystallize, as only heterogeneous recrystallization favours the formation of GBs.

\section{7-Appendix}


We estimated the length of opx and cpx unit cell $c$ parameter for $\mathrm{T}=800^{\circ} \mathrm{C}$ and $\mathrm{P}=0.7$

GPa as:

$$
c=c_{0}\left(1+800 \alpha_{\mathrm{T}}+0.7 \alpha_{\mathrm{P}}\right)
$$

where $c_{0}$ is the value for ambient $\mathrm{P}$ and $\mathrm{T}$ and $\alpha_{\mathrm{T}}$ and $\alpha_{\mathrm{P}}$ expresses the thermal dilatation and compressibility coefficients. For opx, $\alpha_{\mathrm{T}} \approx 0.1610^{-4} /{ }^{\circ} \mathrm{C}$, irrespective of its composition (Frisillo and Buljan 1972; Sueno, et al. 1976) and $\alpha_{\mathrm{P}} \approx-3.510^{-3} /$ GPa (Angel and Hugh-Jones (1994) for enstatite). For $\operatorname{cpx}, \alpha_{\mathrm{T}} \approx 0.0610^{-4} /{ }^{\circ} \mathrm{C}$ (Cameron, et al. (1973) for either hedenbergite of diopside) and $\alpha_{\mathrm{P}} \approx-2.810^{-3} / \mathrm{GPa}$ (Levien and Prewitt (1981) for diopside).

In other words, pressure-dependent variations are similar for cpx and opx, while thermal expansion of opx is much larger than in cpx. In contrast, unit cell parameter $c_{0}$ is consistently larger in cpx (Levien and Prewitt 1981; Salviulo, et al. 1997) than in opx (Angel and Hugh-Jones 1994; Smyth 1973; Sueno, Cameron and Prewitt 1976). To take into account the large compositional dependence of $c_{0}$, we considered compositions as close as possible to ours (Raimbourg, Toyoshima, Harima and Kimura 2008): For opx, Smyth (1973) reported $c_{0}^{\text {opx }}=5.232 \AA$, while for cpx, Salviulo, Secco, Antonini and Piccirillo (1997) reported $c_{0}^{\mathrm{cpx} 1}=5.26 \AA$ and $c_{0}^{\mathrm{cpx} 2}=5.28 \AA$ for two samples of similar composition (VG3187 and VG3185Pc). 
When considering the first value $c_{0}^{\mathrm{cpx} 1}$, parameter $c$ has roughly the same length in opx and in cpx for $\mathrm{T}=800^{\circ} \mathrm{C}$ and $\mathrm{P}=0.7 \mathrm{GPa}$, i.e. no mismatch dislocations are required. For the same P-T conditions, when considering the second value $c_{0}^{\mathrm{cpx} 2}, c^{\mathrm{cpx} 2}$ is larger than $c^{\mathrm{opx}}$ by $\sim 0.2 \%$, which implies dislocations spaced by $250 \mathrm{~nm}$.

These calculations tends to show that $c^{\mathrm{cpx}}>c^{\mathrm{opx}}$ at high $\mathrm{P}$ and $\mathrm{T}$, requiring emplacement of mismatch dislocations along the interface. Our own HRTEM observations of the polarity of regularly spaced dislocations along the interface of a lamellae in a domain devoid of bending show similarly that $c^{\mathrm{cpx}}>c^{\mathrm{opx}}$. On the other hand, the large uncertainties in unit cell parameter at ambient conditions, of the order of the pressure and temperature dependent variations, preclude to precisely assess the density of such mismatch dislocations and we retain therefore only the possible magnitude of dislocation spacing, as of the order of a few hundreds of nanometers.

\section{Bibliography}

Angel RJ, Hugh-Jones DA (1994) Equations of state and thermodynamic properties of enstatite pyroxenes. J. Geophys. Res. 99(B10):19,777-19783

Arita K, Mori M, Ogura K, Motoyoshi Y (1978) The metamorphic rocks and migmatites of the southern part of the Hidaka Metamorphic Belt. Assoc. Geol. Collabor. Japan Monograph 21:27-41

Boullier AM, Gueguen Y (1975) SP-Mylonites: Origin of some mylonites by superplastic flow. Contrib. Mineral. Petr. 50:93-104

Buseck PR, Iijima S (1974) High-resolution electron microscopy of silicates. Am. Mineralogist 59:1-21

Cameron M, Sueno S, Prewitt CT, Papike J (1973) High temperature crystal chemistry of 
acmite, diopside, hedenbergite, jadeite, spodumene and ureyite. Am. Mineral. 58:594-618

Coe RS, Kirby SH (1975) The orthoenstatite to clinoenstatite transformation by shearing and reversion by annealing: Mechanism and potential applications. Contr. Mineral. Petrol. 52(29-55)

Coe RS, Müller WF (1973) Crystallographic orientation of clinoenstatite produced by deformation of orthoenstatite. Science 180:64-66

Drury MR, Pennock G (2007) Subgrain rotation recrystallization in minerals. Materials Science Forum 550:95-104

Duffy TS, Vaughan MT (1988) Elasticity of enstatite and its relationship to crystal structure. J. Geophys. Res. 93(B1):383-391

Duyster J, Stöckhert B (2001) Grain boundary energies in olivine derived from natural microstructures. Contrib. Mineral. Petrol. 140:567-576

Etheridge MA (1975) Deformation and recrystallisation of orthopyroxene from the Giles Complex, central Australia. Tectonophysics 25:87-114

Frisillo AL, Buljan ST (1972) Linear expansion coefficients of orthopyroxene to $1000^{\circ} \mathrm{C}$. J. Geophys. Res. 77:7115-7117

Guillopé M, Poirier JP (1979) Dynamic recrystallization during creep of single-crystalline halite: an experimental study. J. Geophys. Res. 84:5557-5567

Heinemann S, Wirth R, Gottschalk M, Dresen G (2005) Synthetic [100] tilt grain boundaries in forsterite: $9.9^{\circ}$ to $21.5^{\circ}$. Phys. Chem. Minerals 32:229-240

Herwegh M, Kunze K (2002) The influence of nano-scale second-phase particles on deformation of fine grained calcite mylonites. J. Struct. Geol. 24:1463-1478

Hiraga T, Anderson IM, Kohlstedt DL (2004) Grain boundaries as reservoirs of incompatible elements in the Earth's mantle. Nature 427:699-703

Hirth G, Tullis J (1992) Dislocation creep regimes in quartz aggregates. J. Struct. Geol. 14(2):145-159

Hirth JP, Lothe J (1968) Theory of dislocations, vol. McGraw-Hill, p 780

Jolivet L, Miyashita S (1985) The Hidaka Shear Zone (Hokkaido, Japan): Genesis during a right-lateral strike slip movement. Tectonics 4:289-302

Kanagawa K, Shimano H, Hiroi Y (2008) Mylonitic deformation of gabbro in the lower crust: A case study from the Pankenushi gabbro in the Hidaka metamorphic belt of central Hokkaido, Japan. J. Struct. Geol.:doi:10.1016/j.jsg.2008.1005.1007

Kohlstedt DL, Van der Sande JB (1973) Transmission electron microscopy investigation of the defect microstructure of four natural orthopyroxenes. Contr. Mineral. Petrol. 42:169-180 Kuhlmann-Wilsdorf D, Hansen N (1991) Geometrically necessary, incidental and subgrain boundaries. Scripta Metall. Mater. 25:1567-1552 
Levi AA, Smith DA, Wetzel JT (1991) Calculated structures for [001] symmetrical grain boundaries in silicon. J. Appl. Phys. 69:2048-2056

Levien L, Prewitt CT (1981) High-pressure structural study of diopside. Am. Mineral. $66: 315-323$

McLaren AC, Etheridge MA (1976) A transmission electron microscope study of naturally deformed orthopyroxene. I. Slip mechanisms. Contr. Mineral. Petrol. 57:163-177

Miyashita S, Maeda J (1978) The basic plutonic and metamorphic rocks from the northern Hidaka Metamorphic Belts, Hokkaido. Assoc. Geol. Collabor. Japan Monograph 21:43-60

Naze L, Doukhan N, Doukhan J-C, Latrous K (1987) A TEM study of lattice defects in naturally and experimentally deformed orthopyroxenes. Bull. Mineral. 110:497-512

Nicolas A, Poirier JP (1976) Crystalline plasticity and solid state flow in metamorphic rocks, vol. John Wiley \& Sons, London, p 444

Osanai Y, Komatsu M, Owada M (1991) Metamorphism and granite genesis In the Hidaka Metamorphic Belt, Hokkaido, Japan. J. Metamorp. Geol. 9(2):111-124

Passchier CW, Trouw RAJ (1996) Microtectonics, vol. Springer-Verlag, Berlin Heidelberg, p 289

Pennock G (2005) The development of subgrain misorientations with strain in dry synthetic $\mathrm{NaCl}$ measured using EBSD. J. Struct. Geol. 27:2159-2170

Poirier JP (1995) Plastic rheology of crystals. In: Mineral Physics and crystallography, a handbook of physical constants, vol. AGU, pp 237-247

Precigout J, Gueydan F, Gapais D, Garrido CJ, Essaifi A (2007) Strain localisation in the subcontinental mantle - a ductile alternative to the brittle mantle. Tectonophysics 445:318-336

Raimbourg H, Toyoshima T, Harima Y, Kimura G (2008) Grain size reduction mechanisms and rheological consequences in high-temperature gabbro mylonites of Hidaka, Hokkaido Earth Planet. Sc. Lett. 267:637-653

Raleigh CB, Kirby S, Carter NL, Ave Lallemant HG (1971) Slip and the clinoenstatite transformation as competing rate processes in enstatite. J. Geophys. Res. 76(17):4,011-014,022

Ramsay JG (1967) Folding and fracturing of rocks. In, vol. McGraw-Hill Book Company, New York, p 568

Read WT (1953) Dislocations in crystals, vol. McGraw-Hill, New York

Salviulo G, Secco L, Antonini P, Piccirillo EM (1997) C2/c pyroxene from two alkaline sodic suites (Western Ross Embayment-Antarctica): crystal chemical characterization and its petrologic significance. Mineral. Mag. 61:423-439

Sato Y, Mizoguchi T, Oba F, Ikuhara Y, Yamamoto T (2005) Arrangement of multiple 
structural units in a [0001] $\Sigma 49$ tilt grain boundary in ZnO. Phys. Rev. B 72:10.1103/PhysRevB.1172.064109

Sellars CM (1978) Recrystallization of metals during hot deformation. Phil. Trans. R. Soc. Lond. A 288(1350):147-158

Skemer P, Karato S-I (2007) Effects of solute segregation on the grain-growth kinetics of orthopyroxene with implications for the deformation of the upper mantle. Phys. Earth Planet. In. 164:186-196

Smith DA (1996) On the general grain boundary. Interface Science 4:11-27

Smyth JR (1973) An orthopyroxene structure up to 850 C. Am. Mineral. 58:636-648

Steuten JM, Van Roermund HLM (1989) An optical and electron microscopy study of defect microstructures in naturally deformed orthopyroxene. Tectonophysics 157:331-338

Sueno S, Cameron M, Prewitt CT (1976) Orthoferrosilite: high temperature crystal chemistry. Am. Mineral. 61:38-53

Timoshenko S, Goodier JN (1951) Theory of elasticity, vol. McGraw-Hill, New York

Toyoshima T (1991) Tectonic evolution of the Hidaka metamorphic belt and its implication in late Cretaceous-Middle Tertiary Tectonics of Hokkaido, Japan. In: Science reports of Niigata University Series E, Geology and Mineralogy, No. 8, vol., pp 1-107

Toyoshima T, Komatsu M, Niizato T (2000) Granulite-grade gabbroic mylonites and crustal-scale decollement in a deep crust exposed in the Hidaka metamorphic belt. In: Geol. Soc. Japan Meeting, vol., p 277

Toyoshima T, Komatsu M, Shimura T (1994) Tectonic evolution of lower crustal rocks in an exposed magmatic arc section in the Hidaka metamorphic belt, Hokkaido, northern Japan. Island Arc 3:182-198

Tullis J, Yund RA (1985) Dynamic recrystallization of feldspar: a mechanism for ductile shear zone formation. Geology 13:238-241

Van Duysen JC, Doukhan N, Doukhan JC (1985) Transmission electron microscope study of dislocations in orthopyroxene (Mg, Fe)2Si206. Phys. Chem. Minerals 12:39-44

Wegner MW, Christie JM (1985) Chemical etching of amphiboles and pyroxenes. Phys. Chem. Minerals 12:86-89

White S (1977) Geological significance of recovery and recrystallization processes in quartz. Tectonophysics 39:143-170

Figure 1: Internal folding of an opx porphyroclast (XZ section, with horizontal dextral 
shear). (A) Fore-scattered electron image of opx 47a2-px2 with the localization of EBSD analyses. As seen in the interpretative sketch below, traces of (100) planes (figured by the line within opx) are bent similarly to the grain shape itself. (B) Pole figure of crystal orientations in the sample coordinate $(\mathrm{X}, \mathrm{Y}$ and $\mathrm{Z}$ the kinematic axes indicated by small squares). The $\boldsymbol{b}$-axes are concentrated near the Y axis, while $\boldsymbol{a}$ - and $\boldsymbol{c}$-axes are scattered within a girdle. The points of extreme orientation 1,8 and 31 are shown. The rotation axis between crystal orientations 8 and 31, shown as a star, is really close to $\boldsymbol{b}$-axis (associated rotation angle $\approx 40^{\circ}$ ). Note that the dark, tortuous lines in opx in (A) are cracks, whereas GBs appear as sharp variations in crystal orientation contrast.

Figure 2: Optical microscope image in reflected light of the etched surface of the opx porphyroclasts. GBs are apparent as thin black lines separating misoriented domains of undistorted opx. (A) Straight boundaries (white triangles), at large angle to the traces of opx (100) planes underlined by the cpx exsolutions (black triangles). (B) Curved GBs (roughly horizontal in the picture), at low angle to the traces of (100) opx planes. This curved GB is connected into a straight GB (subvertical in the picture) at the red triangle. The misorientation between upper and lower domain increases from right to left. (C) 
Homogeneously folded opx, where lattice curvature is smooth and no etched GB is visible.

Figure 3: (A) Fore-scatter image and (B) EBSD map of homogeneously folded opx. Within opx domains, points where crystal orientation could not be detected appear in green. The pole figure $(\mathrm{C})$, which consists of the points of the map along the X-Y transects, shows that rotations are principally around the $\boldsymbol{b}$-axis. Lattice curvature is homogeneously distributed, as evidenced by (i) the progressive misorientation, along $\mathrm{X}-\mathrm{Y}$ profile, with respect to point $\mathrm{X}$ (D) and (ii) the absence of visible GB on the EBSD map. Note that the change in color from blue to orange corresponds simply to the change in azimuth of the $c$-axis $\left(+/-180^{\circ}\right.$, see C). Step size for the map is $3 \mu \mathrm{m}$.

Figure 4: Domains of incipient (A) and extensive (B) recrystallization within opx porphyroclasts. (A') and (B'): Pole figures of recrystallized grains and parent porphyroclast, showing common $\boldsymbol{b}$-axis for grains in (A') and random orientation in (B'). (A") and (B"): Inverse pole figure of misorientation axes between adjacent grains, for increasing misorientation ranges. While in (A") misorientation axes plot close to $\boldsymbol{b}$ axes irrespective of misorientation angle, in (B") they show no preferred crystallographic 
orientation.

Figure 5: TEM bright-field images and corresponding diffraction conditions (upper-right) of a low-angle GB. The boundary appears as made of regularly spaced dislocations, apparent when $h 0 l$ reflections (small $h$ index and $l= \pm 2, \pm 4, .$. ) are strongly excited (A) but invisible when $h 00$ reflections are strongly excited (B). The misorientation $\left(\sim 0.5^{\circ}\right)$ was estimated from the diffraction pattern in TEM. Rotation is principally around the $\boldsymbol{b}$-axis of opx, with a minor component around the $\boldsymbol{c}$-axis.

Figure 6: Comparison between measured dislocation spacing and theoretical value for low angle tilt wall boundaries (Hirth and Lothe 1968). We analyzed two kinds of GB, either perpendicular or parallel to opx (100) planes traces and considered c=5.24 $\AA$ or $\mathrm{a}=18.2 \AA$, respectively, as Burgers vector length in Eq. 1. As dislocation density is slightly variable along a boundary, for each boundary considered (i.e. the different symbols), we made several estimations of the spacing.

Figure 7: Detail of the dislocations within a straight LAGB with the misorientation $\sim 0.5^{\circ}$ and the tilt axis close to the $\boldsymbol{b}$-axis. (A) Bright-field image: Regularly spaced 
dislocations are constituted of two strain contrasts, suggeting that each dislocation is dissociated. (B) HRTEM view of one of these dislocations, with beam parallel to the $\boldsymbol{b}$ axis: In the image, the opx crystal is imaged with intense $d_{200}$ lattice fringes, whereas the area between the two strain contrasts indicated by the arrowheads has fringes with a half space. This is interpreted as the local transformation of ortho- to clino-enstatite where $d_{100}$ is half that of ortho-enstatite (Buseck and Iijima 1974). One can also note that the clino-enstatite domain (enclosed in dashed white line in Fig. 7B) is not restricted to the interval between the two partials but extends further outside of it, as apparent in the half-spaced fringes with three dark lines, interpreted as clino-enstatite with a unit cell width.

Figure 8: (A) TEM bright field image and (B) sketch of a LAGB (thick black line) at low angle with opx (100) plane traces (Note the presence of an additional GB, with lower misorientation, indicated in (B) as a dotted line). (C) to (E) Detail views of the LAGB. (C) Portions of the boundary with straight segments perpendicular to (100) plane traces, with regularly spaced dislocations (white triangles). (D) and (E) Portions of the boundary at low angle to (100) plane traces, with a much irregular distribution of dislocations. In the lower left section of (E), dislocation lines (white triangles) seem to 
be inclined with respect to beam direction (close to opx $\boldsymbol{b}$-axis). Dislocation spacing was estimated on the upper right section of $(E)$.

Figure 9: (A-B) TEM bright field inages and corresponding diffraction conditions (upper-right) of a medium-angle grain boundary. The boundary appears as a continuous thin line, with strain apparent when $h 0 l$ reflections (small $h$ index and $l= \pm 2, \pm 4, .$. ) are strongly excited (A) and invisible when $h 00$ reflections are strongly excited (B). The misorientation is of the order of $7^{\circ}$, principally around opx $\boldsymbol{b}$-axis. (B) HRTEM image of the boundary. In the lower right portion of the image, where the specimen is thin enough to make correspondence between the contrast and structure, the boundary is composed of alterning zones where the lattice planes are either continuous or partially/completely disrupted. The pseudo-periodicity (white triangles) is of the order of $3 \boldsymbol{a}$, i.e. $5.5 \mathrm{~nm}$, close to $4.3 \mathrm{~nm}$, expected dislocation spacing for a $7^{\circ}$ dislocation tilt wall.

Figure 10: (A) TEM bright field images and corresponding diffraction conditions (upper-right) of a medium-angle grain boundary with misorientation of the order of $11^{\circ}$, principally around opx $\boldsymbol{b}$ axis. The boundary appears as a continuous thin line, with 
weak strain apparent only when $h 0 l$ reflections (small $h$ index and $l= \pm 2, \pm 4, .$. ) are strongly excited (left).

Figure 11: Structure of a GB with $21^{\circ}$ misorientation. (A) Optical reflected light: the boundary appears roughly linear, though at small scale it is composed of segments anchored on cpx exsolutions. In addition, in the vicinity of the boundary, cpx is exsolved as tiny and elongated grains. (B) HRTEM image of the boundary in the vicinity of an exsolved cpx grain. Cpx exsolution shares (100 planes with Opx1. The HAGB, which separates Opx 2 from Opx 1 and Cpx appears as a narrow, bright zone, interpreted as incoherent material. (C) Along the same boundary, in the vicinity of image (B): The bright zone is very reduced and is bordered, within surrounding Opx 1 and 2, by a "band" where silicate chains are visible but where opx is much darker. Upper right: diffraction image with $h 00$ planes excited, showing the large rotation about $\boldsymbol{b}$-axis. (D) EBSD pole figure of the two sides of the boundary, showing that the rotation is about $\boldsymbol{b}$-axis $(\mathrm{X}, \mathrm{Y}$ and $\mathrm{Z}$ refer not to kinematic axes but to the arbitrary axes of image (A)). As HRTEM image is also acquired with $\boldsymbol{b}$-axis perpendicular to the plane of the image, apparent angle between $\boldsymbol{a}$-planes and the boundary can be considered as true angle, and the boundary is close to symmetric position with respect to the two adjacent 
opx domains.

Figure 12: Angle, in the section plane, between the trace of the GB and the trace of the bissector of opx (100) planes planes from the adjacent opx domains.

Fig. 13: Dislocation density in a folded opx. (A) Etched cpx exsolution lamellae highlight the smooth bending of opx lattice, with a curvature radius $\mathrm{R}=700 \mu \mathrm{m}$. Apart from a straight LAGB (indicated with the black triangles) visible in the left, none is apparent in the folded area. (B) Preferential dissolution during chemical etching of the sample surface unraveled cpx exsolution lamellae (trench) and dislocations (pit). While some etch pits are isolated in homogeneous opx, some seem to be aligned in a direction parallel to cpx lamellae and sometimes elongated along this direction. We interpret the former as dislocations in opx and the latter as either dislocations at cpx-opx interface or as thin cpx lamellae heterogeneously etched. (C) In the folded domain, dislocations in the bulk opx are few, while they are highly concentrated along the cpx-opx interface. Density of dislocations in bulk opx, estimated either from (B) or (C), is at most $1.2 / \mu \mathrm{m}^{2}$, half of Eq. 2 prediction $\left(\sim 2.7 \mu \mathrm{m}^{-2}\right.$, using the curvature shown in (A)). Note that our estimations of both opx lattice curvature radius and actual dislocation density integrate a 
correction for the angle between $\boldsymbol{b}$-axis and normal to the sample surface. (A) Optical microscope, reflected light (B) SEM and (C) TEM bright field.

Figure 14: Bright-field TEM image showing (100)[001] dislocations (white triangles) concentrated on the surface of a cpx exsolution lamellae (black bands extending out of the micrograph) in two adjacent areas. It is observed (especially in the upper image) that a single dislocation is also dissociated into two partials. The dislocation density varies between the two areas but also between upper and lower surfaces of the lamellae. Dislocation spacing $d$ was calculated for the upper surface in the two areas.

Figure 15: (A) Model of opx flexural slip folding, where the equivalent of the folded layers and slip planes are the opx layers and cpx exsolutions, respectively. (B) Considering a folded opx layer, an initial segment of length 1 is extended (shortened) to $1\left(1+\frac{t}{2 R}\right)\left(1\left(1-\frac{t}{2 R}\right)\right)$ on the extrados (intrados) of the layer. (C) The mismatch in (001) planes between upper/lower surfaces of opx layers and cpx exsolution involves the presence of (100)[001] dislocations (i.e. extra (001) half-planes), with a spacing given by $1\left(1+\frac{t}{2 R}\right)-1\left(1-\frac{t}{2 R}\right)=c \Rightarrow 1=\frac{c R}{t}$. 
Figure Supplementary material 1: HRTEM image of cpx exsolution and surrounding opx, with the incident beam parallel to the $\boldsymbol{b}$-axis. Note the presence of localized strain (dark zones) within the lamellae and on its right boundary, which corresponds to (100)[001] dislocation.

Figure Supplementary material 2: Gradients in composition associated with recrystallization. (A) Optical microscope picture in reflected light, (B) sketch and (C) EPMA mapping of Ca distribution within a deformed opx porphyroclast. Recrystallized opx, either within the porphyroclast ("intra-opx deformed domain") or on its rim ("small opx domain") have a lower Ca content than the porphyroclast ("coherent opx domain"). Furthermore, within the recrystallized grains on the upper right of (A), grain boundaries are visible in $(\mathrm{C})$ because of their low Ca concentration compared with the grains interiors. Within recrystallized zones, abundant cpx grains probably result from the depletion in $\mathrm{Ca}$ of the opx. Note that when considering a single boundary cutting across the opx, the Ca-depletion is visible only when the misorientation is very large ("GB1"), while no chemical heterogeneity is apparent for a lower misorientation ("GB2"). 
Figure Supplementary material 3: Mixed origin of dislocations at cpx-opx interfaces. In the thermal mismatch model by Van Duysen, Doukhan and Doukhan (1985), dislocations of opposite sign accommodate at the cpx-opx interface the difference in plane density $\left(\mathrm{d}_{001}^{\mathrm{cpx}}<\mathrm{d}_{001}^{\mathrm{opx}}\right)$, acquired during cooling. In the flexural slip model, dislocations of the same sign accommodate the lattice curvature. In contrast to thermal mismatch model, dislocation density needs not to be the same on upper and lower interface. The actual dislocation density is the sum of the two models, after recombination of dislocations of opposite sign on a given interface. 


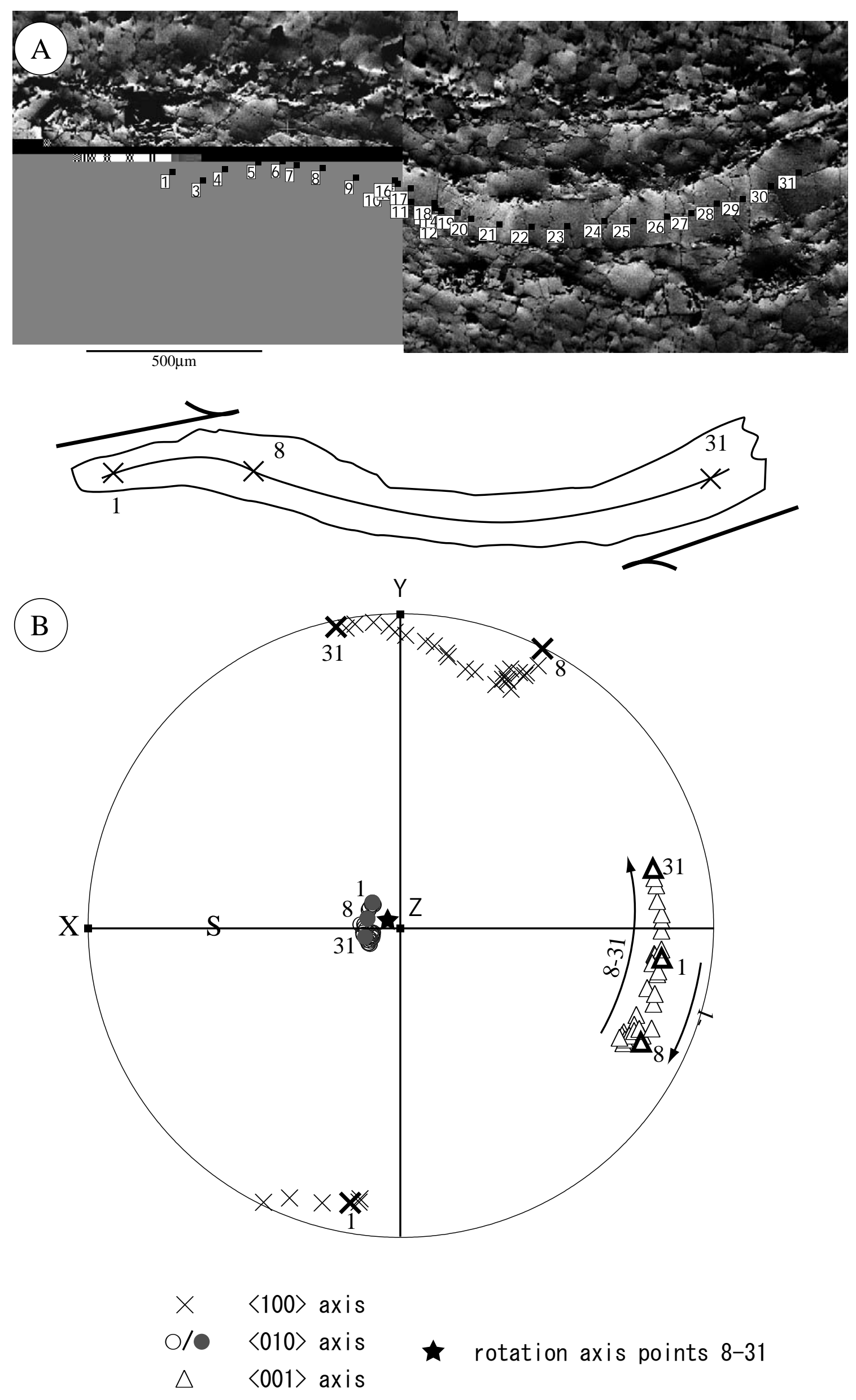



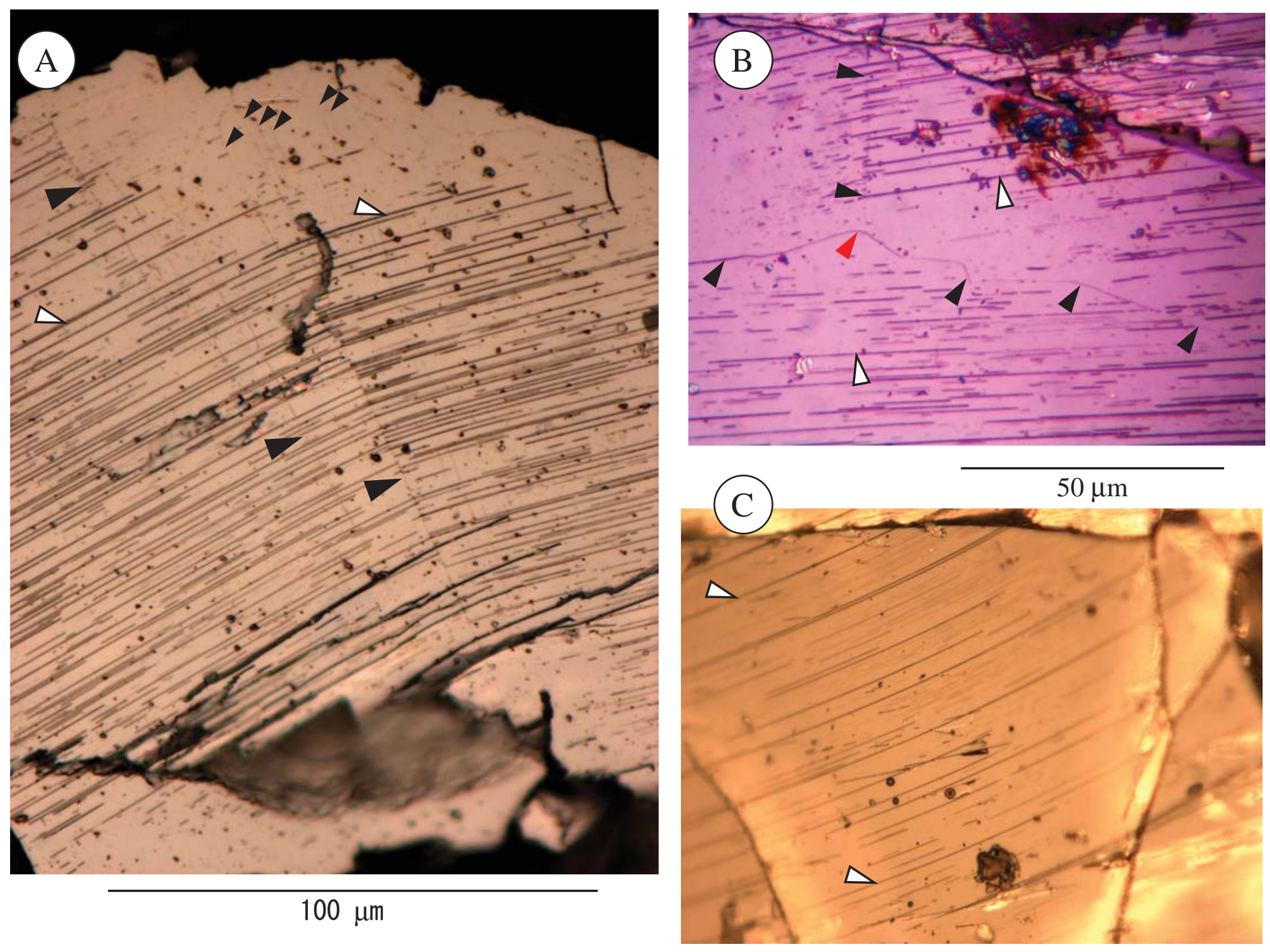

Trace of the grain boundary

$\triangle \quad$ Cpx exsolution

$50 \mu \mathrm{m}$ $\triangle$

Cpx exsolution 
$500 \mu \mathrm{m}$

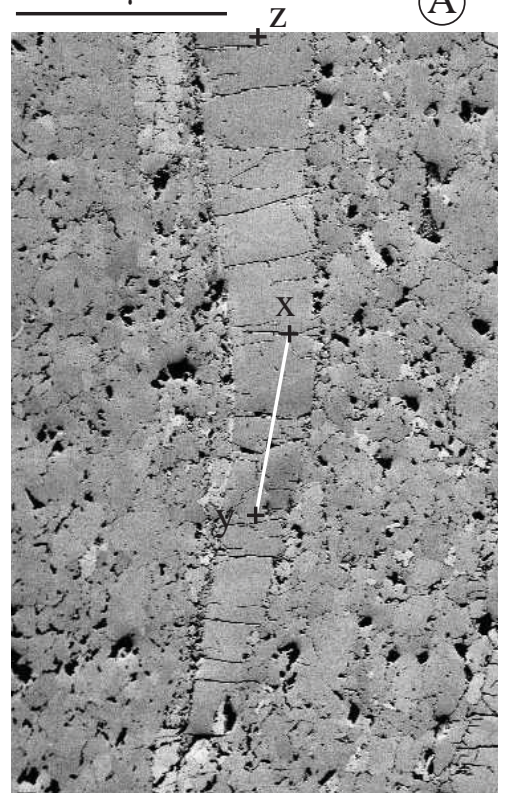

(B)

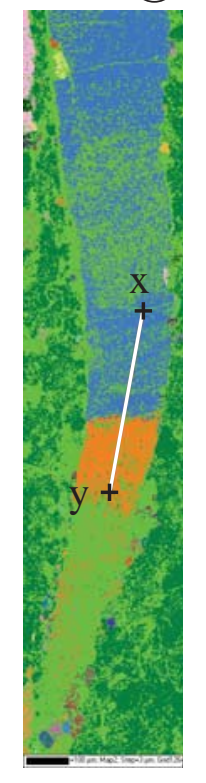

(C)
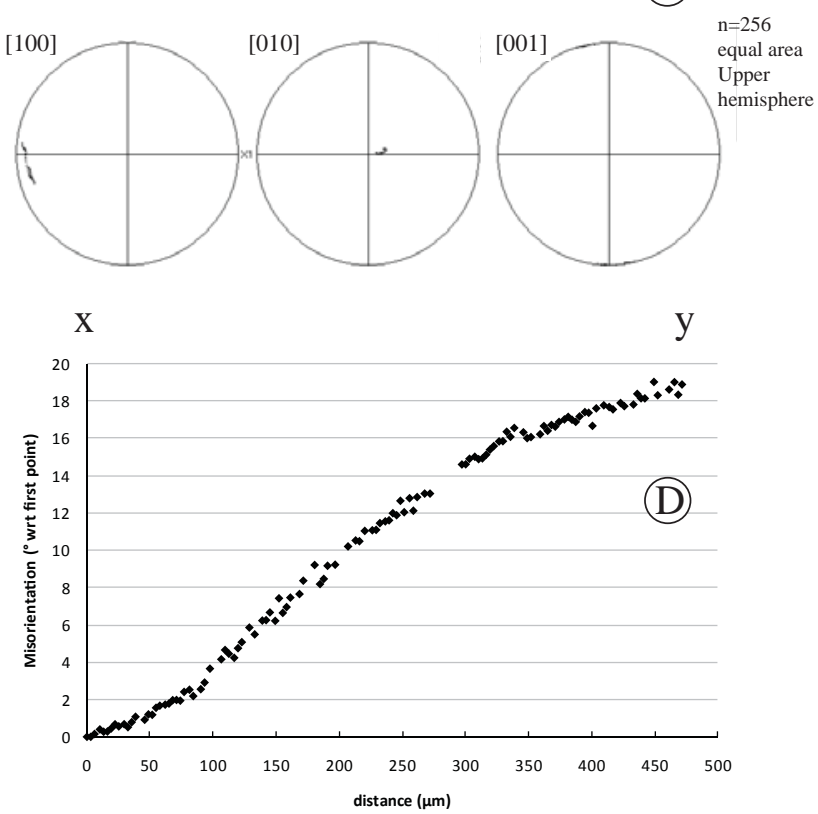

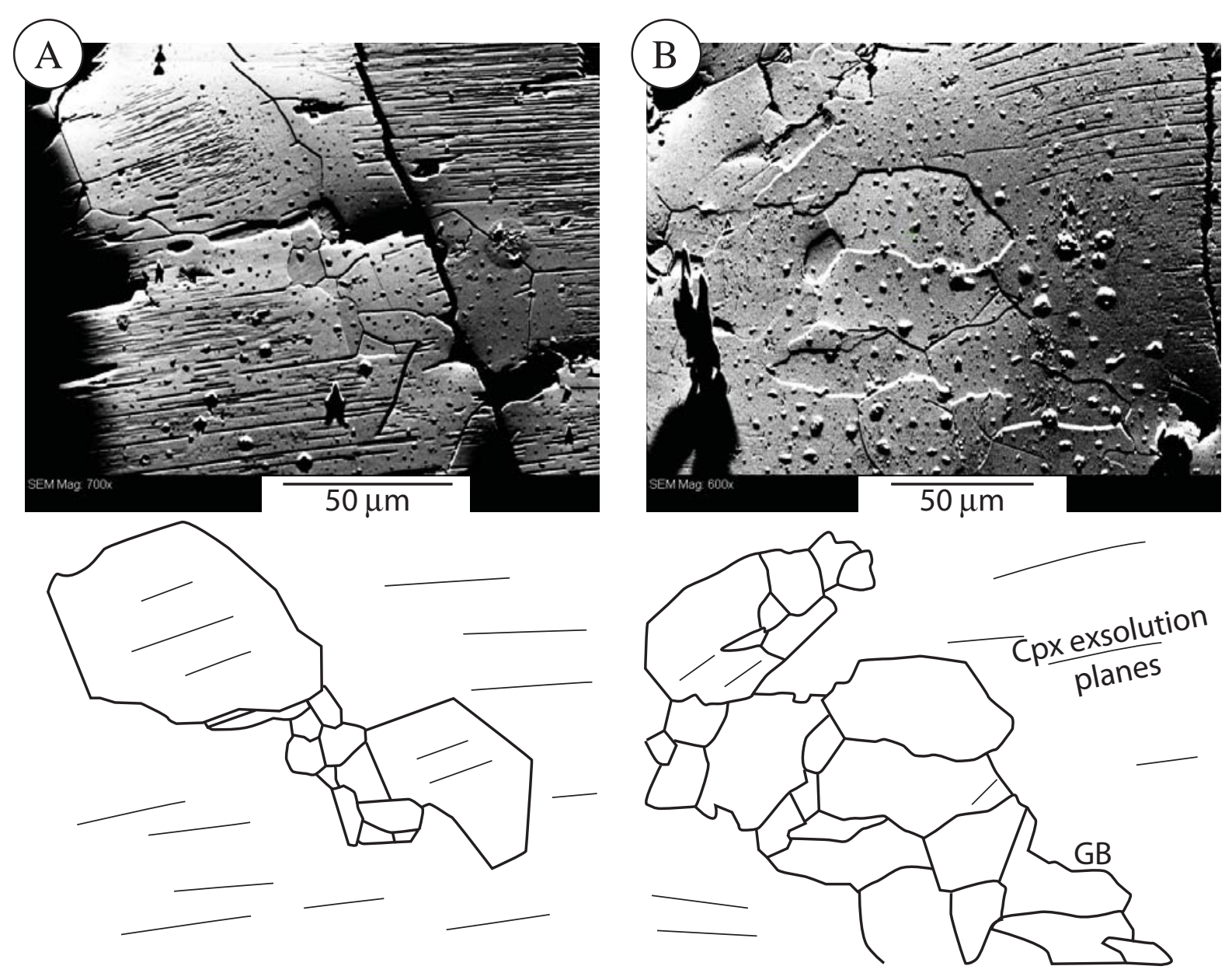

(A)

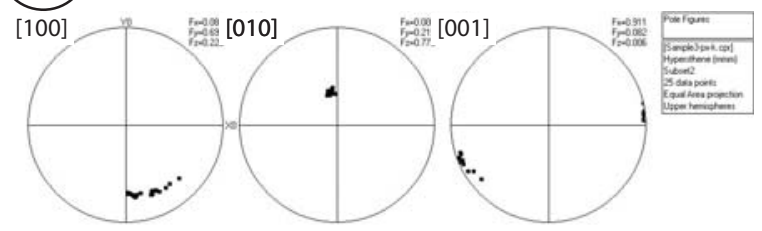

(A.)

(B)

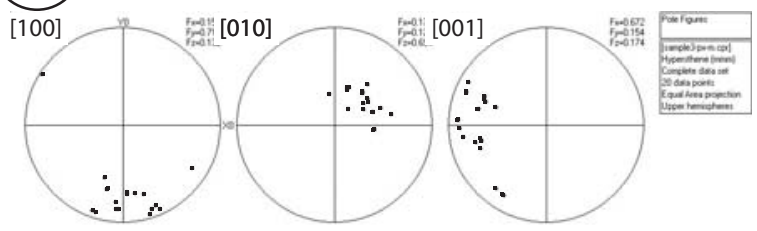

(B)
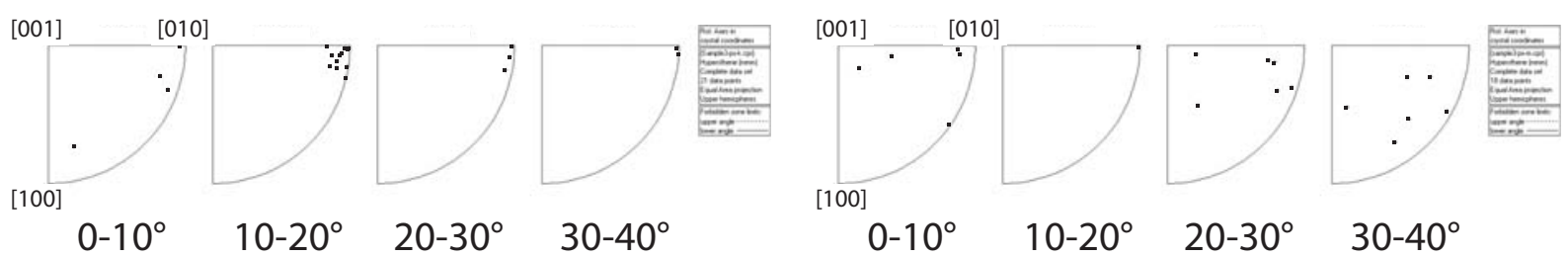


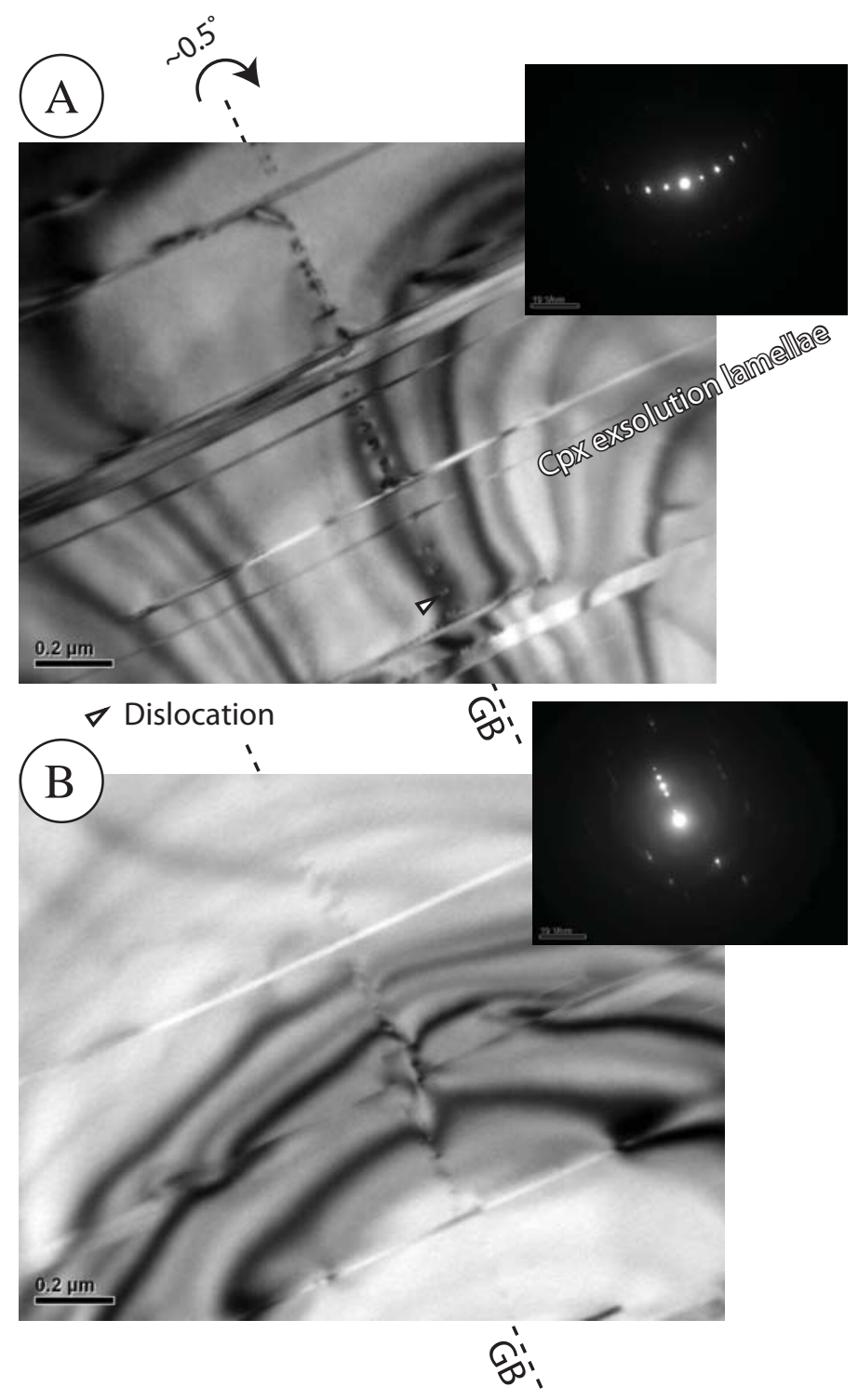

Fig. 5 


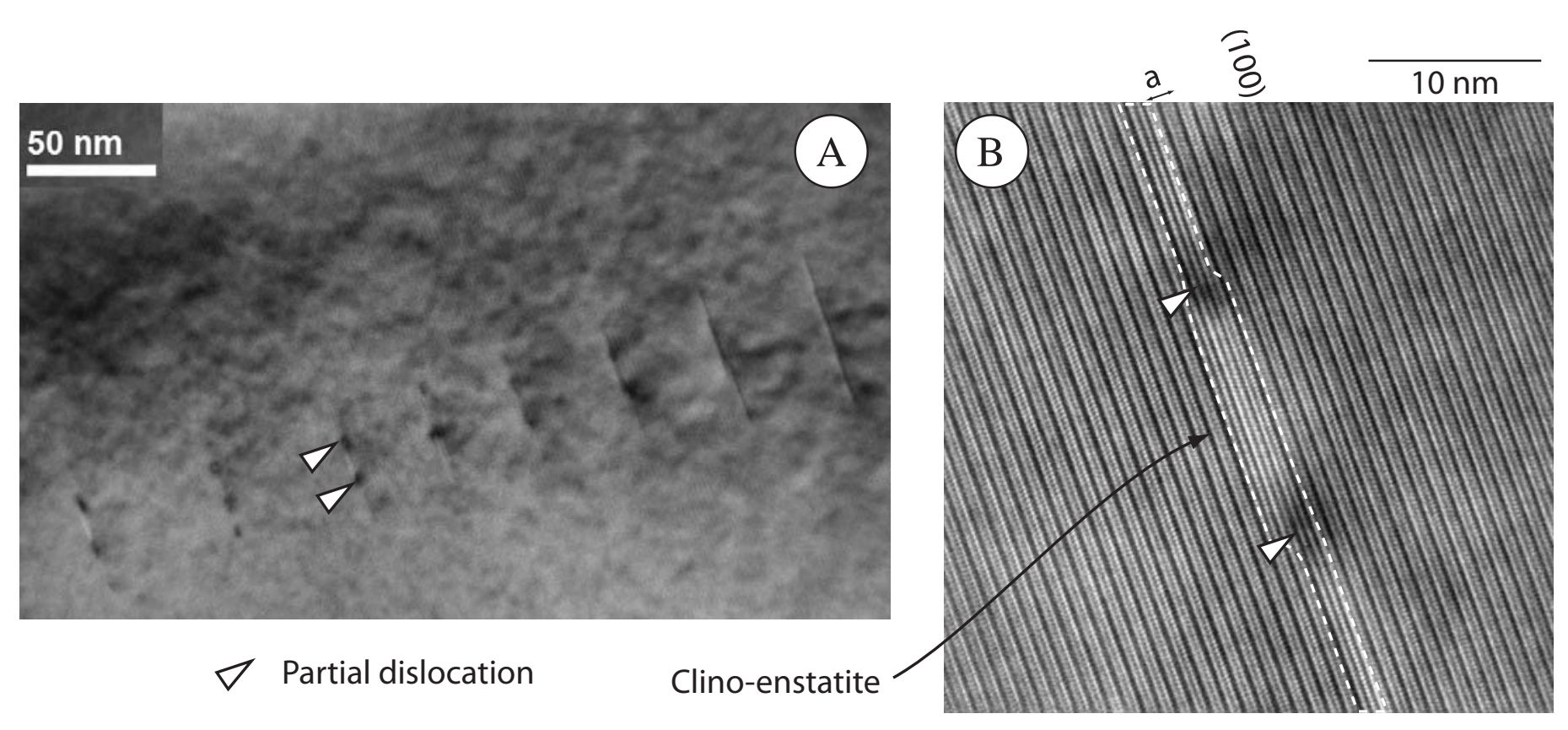



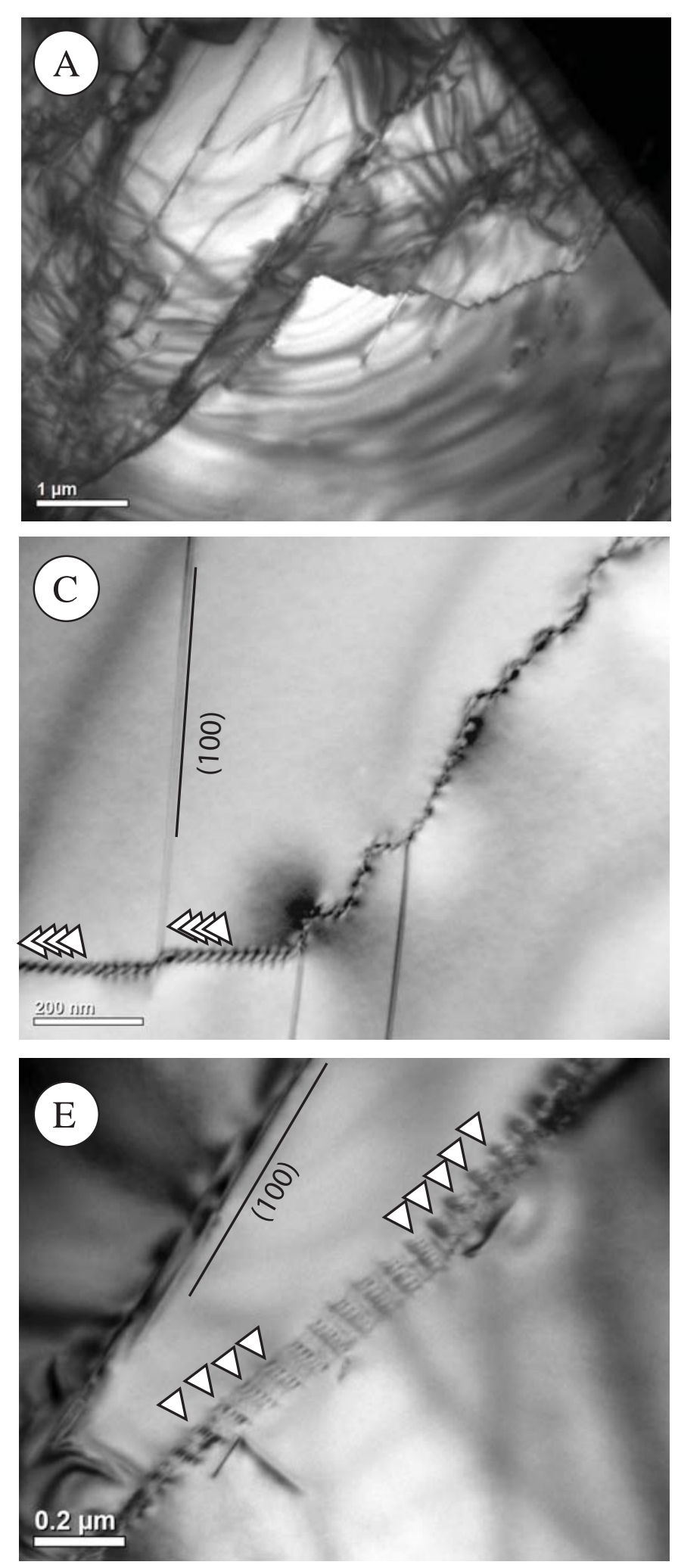
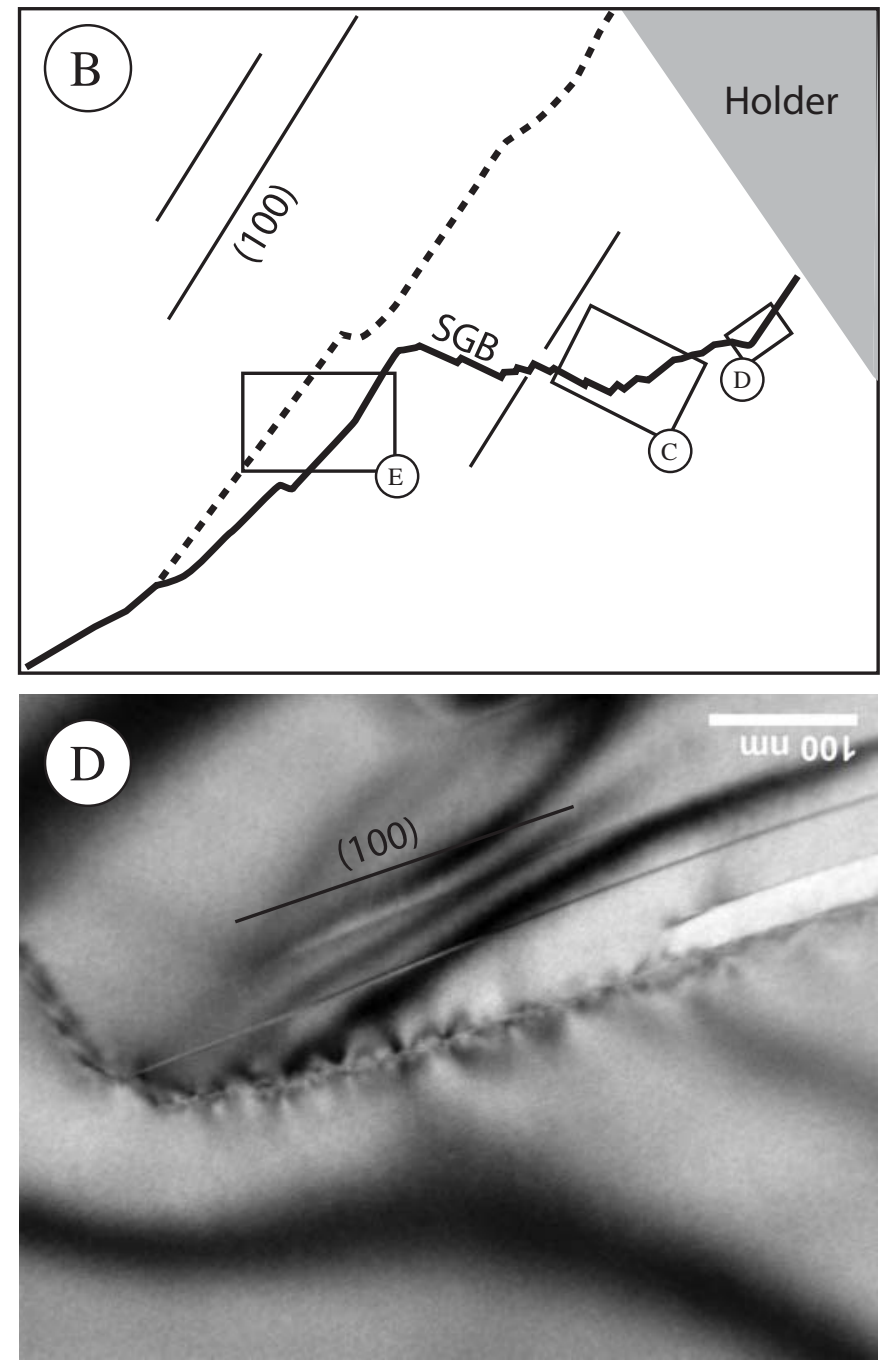

$\triangleleft$ Dislocation 


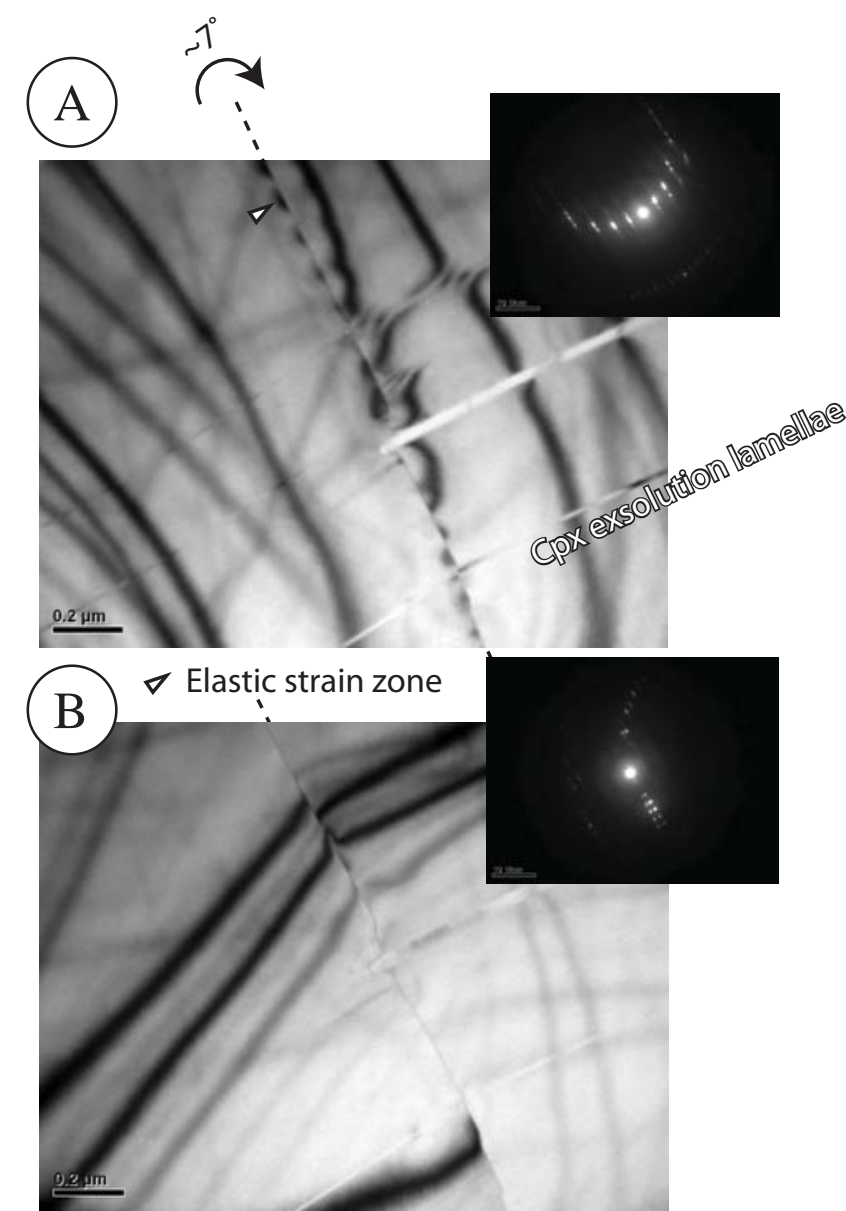

S:

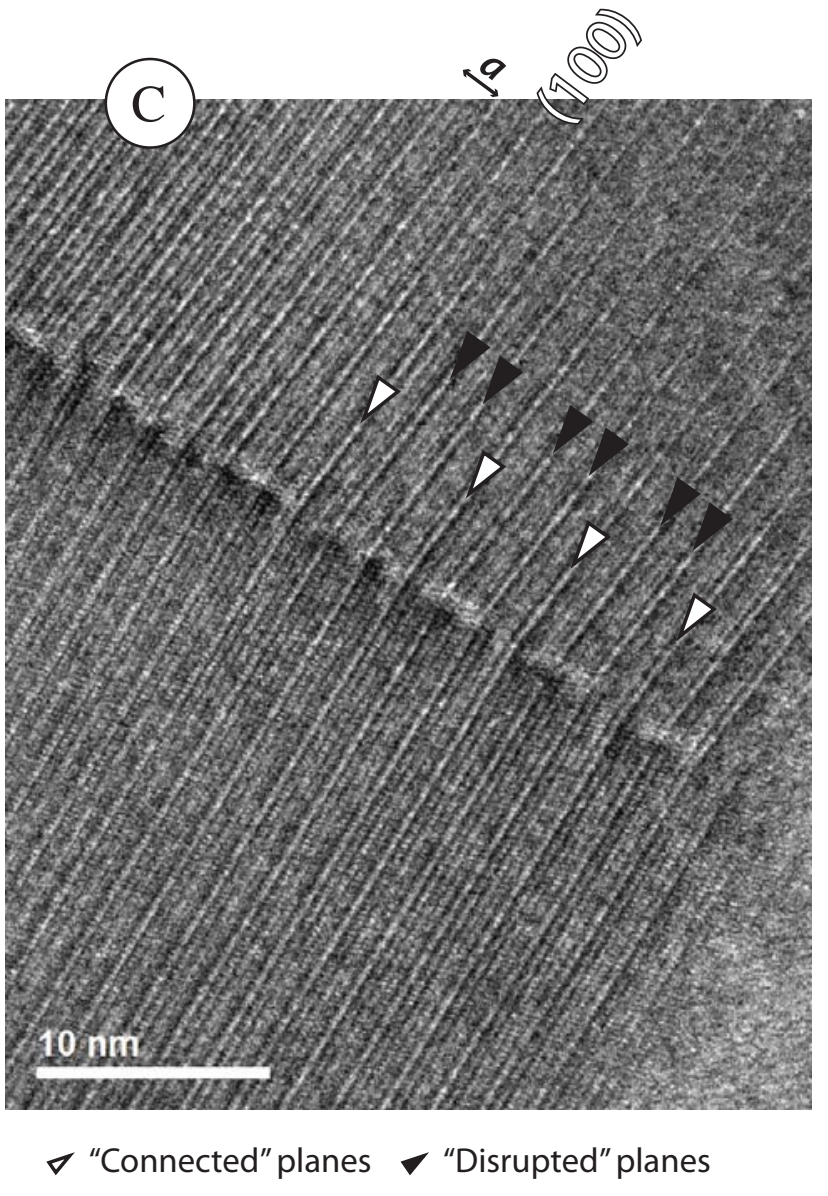

$\nabla$ "Connected" planes $\checkmark$ "Disrupted" planes 


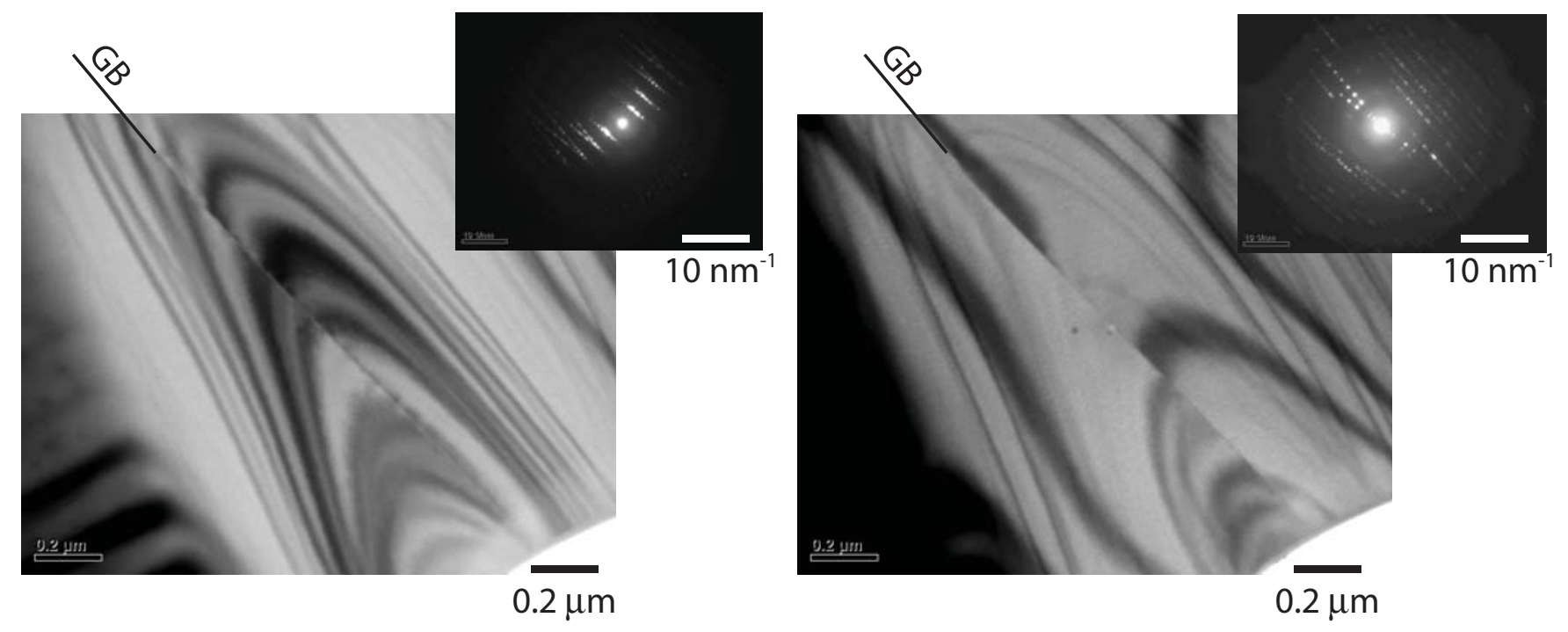



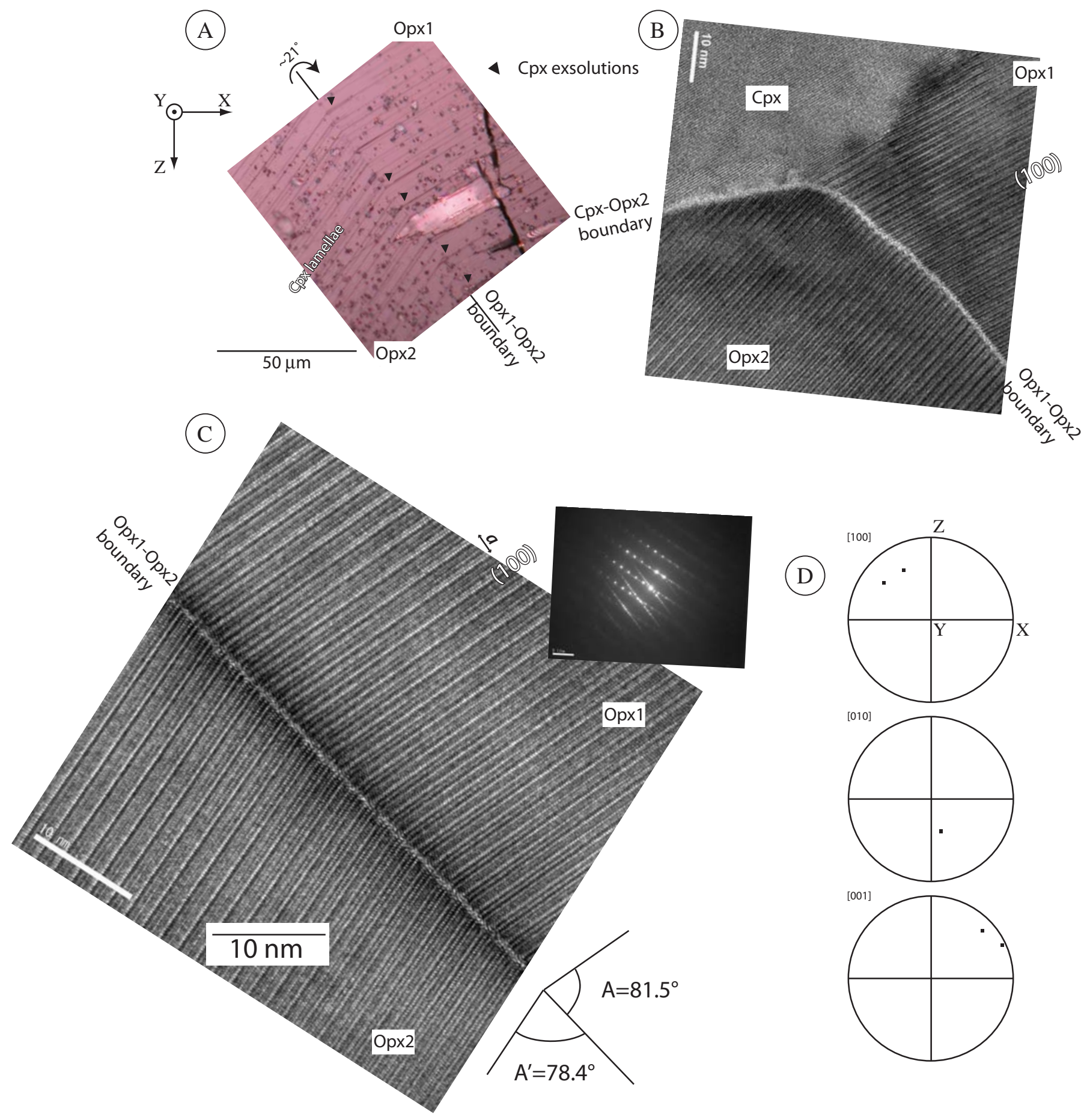

(D)
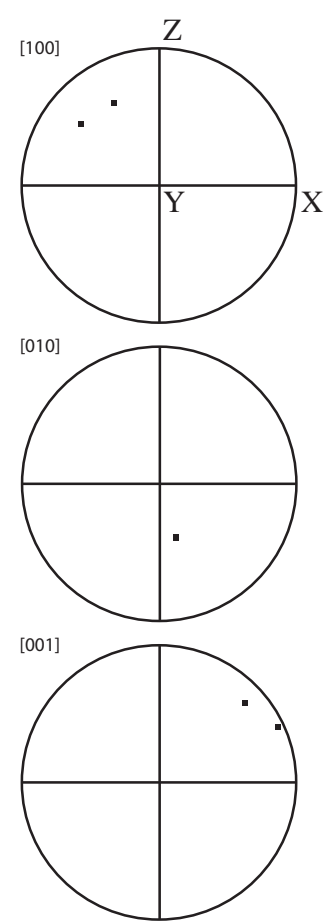


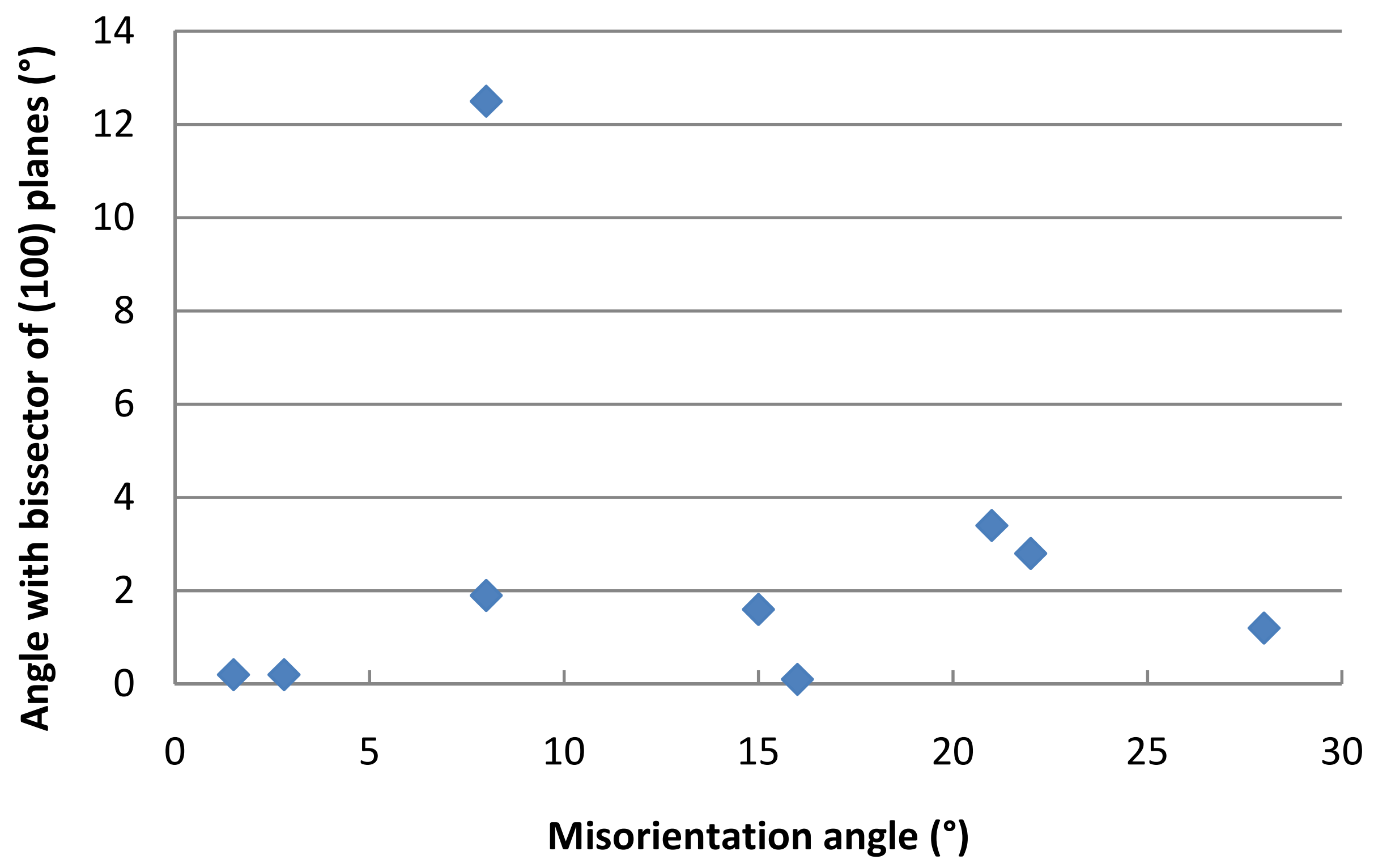



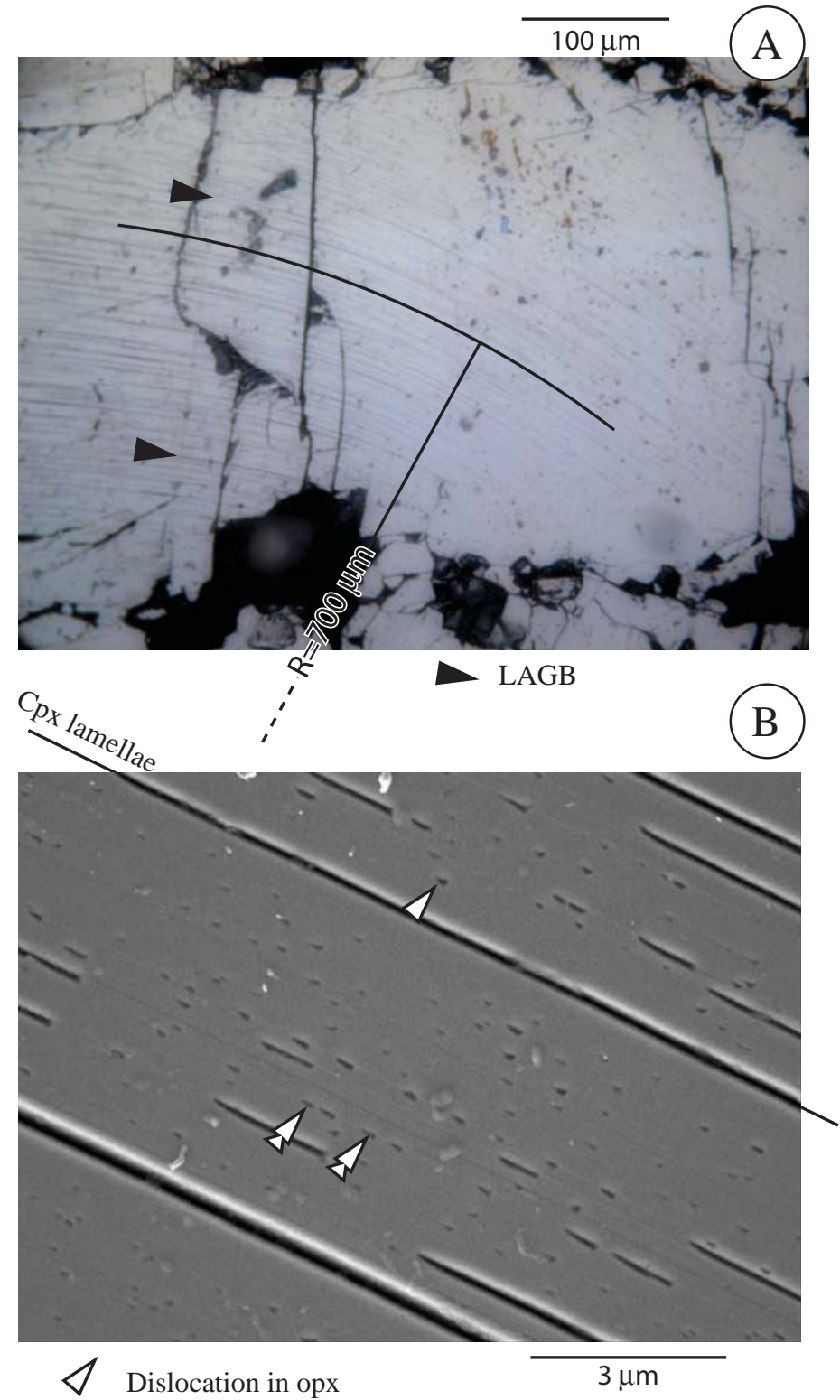

$\$$ Dislocation at opx-cpx interface / Cpx lamellae

(C)

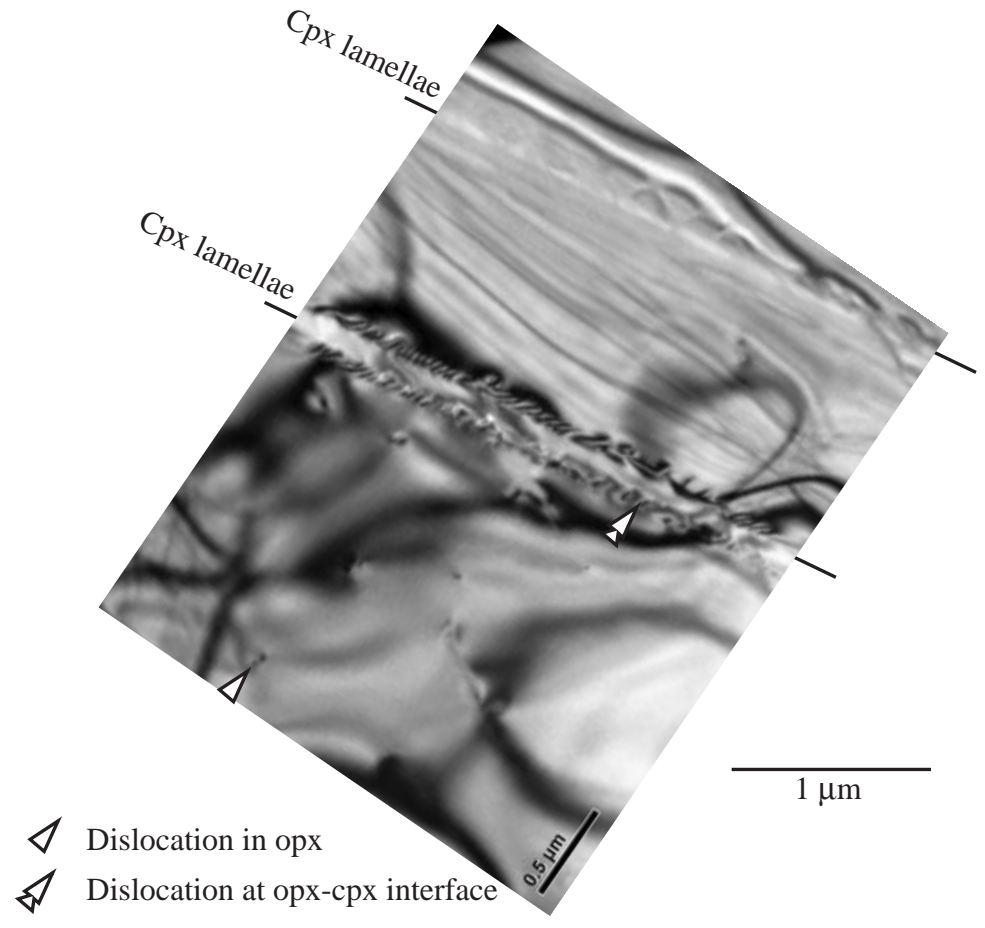

Fig. 13 


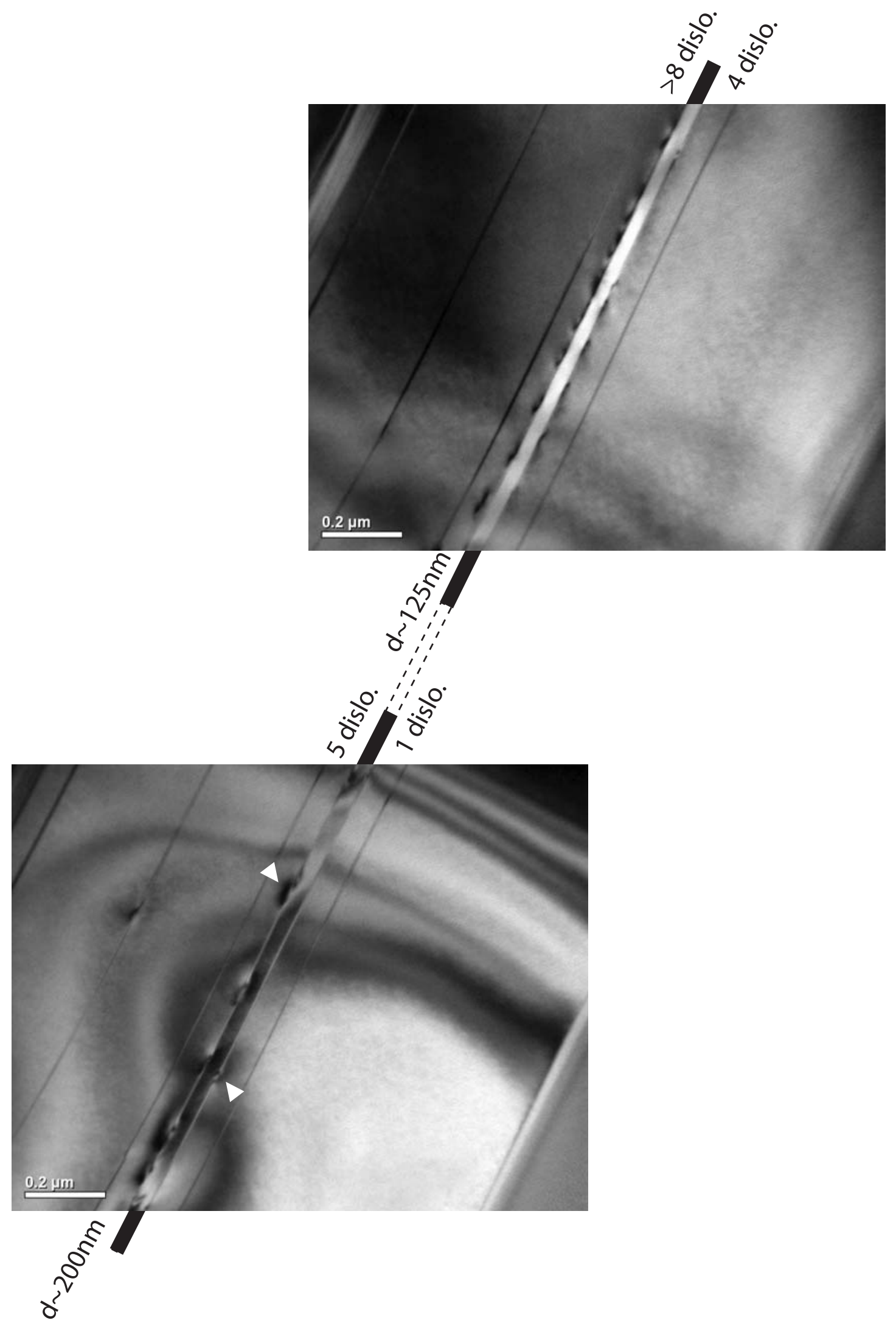




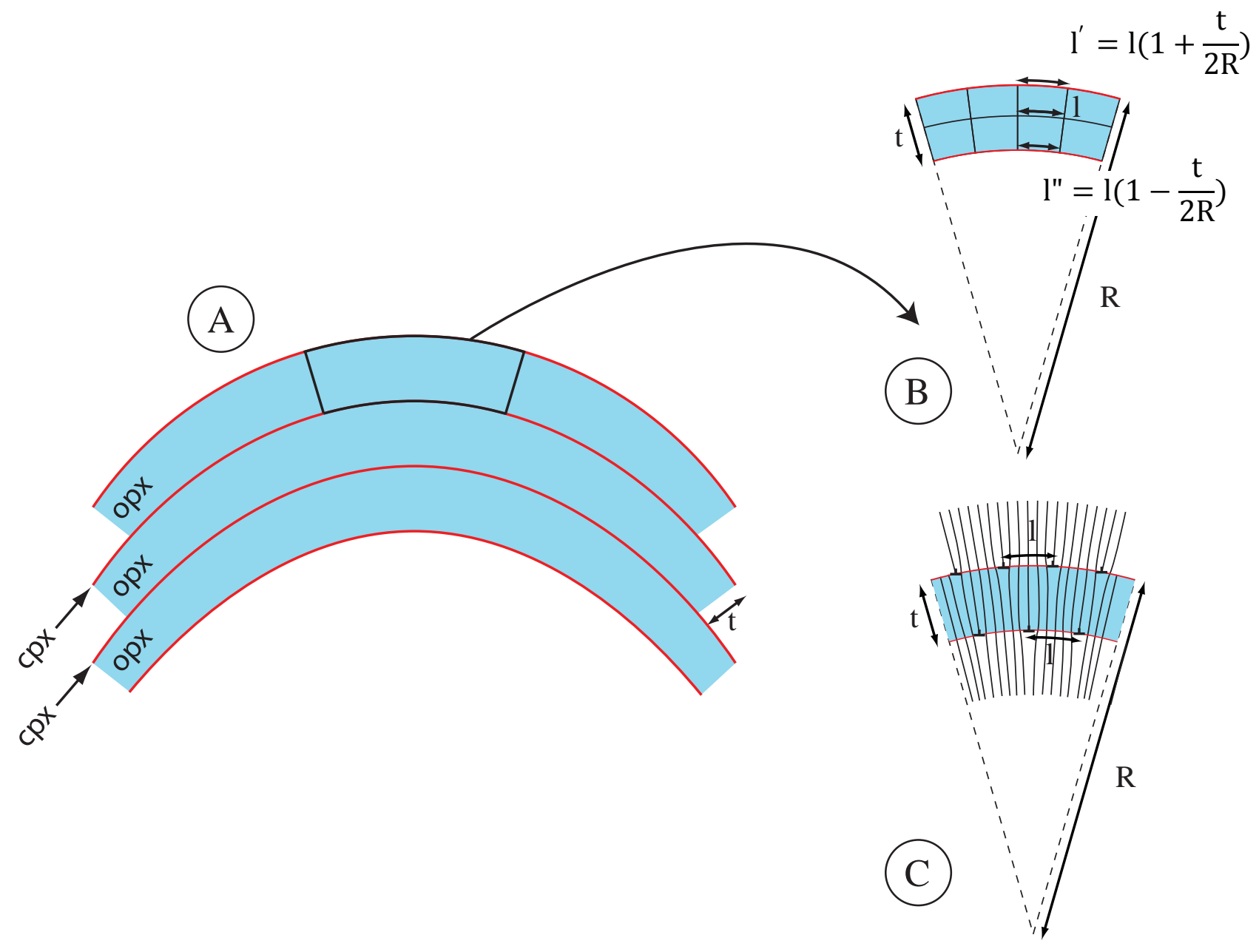




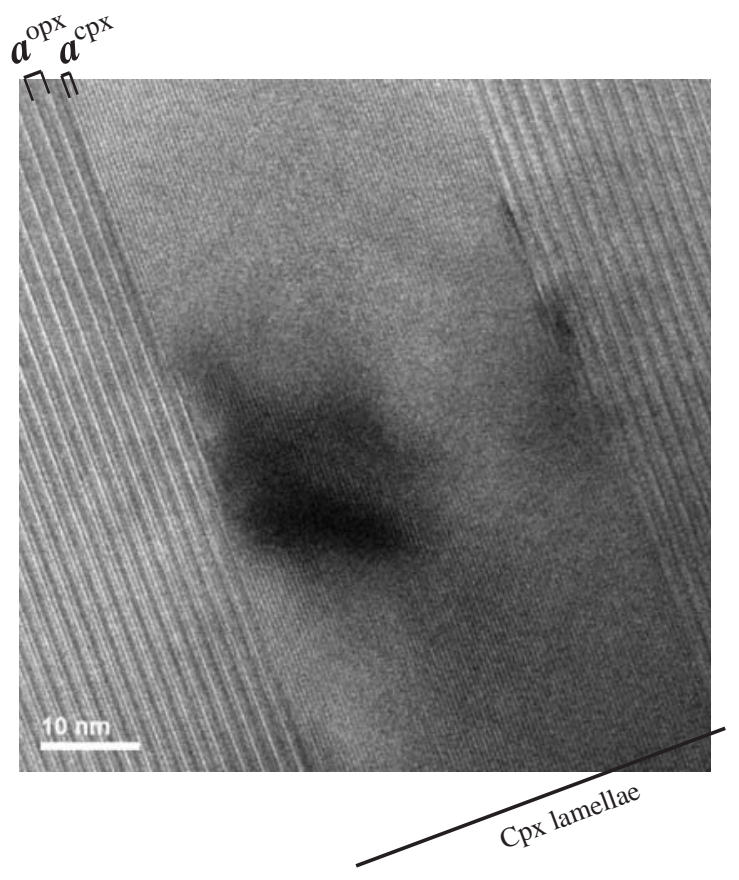

Figure Supplementary material 1 

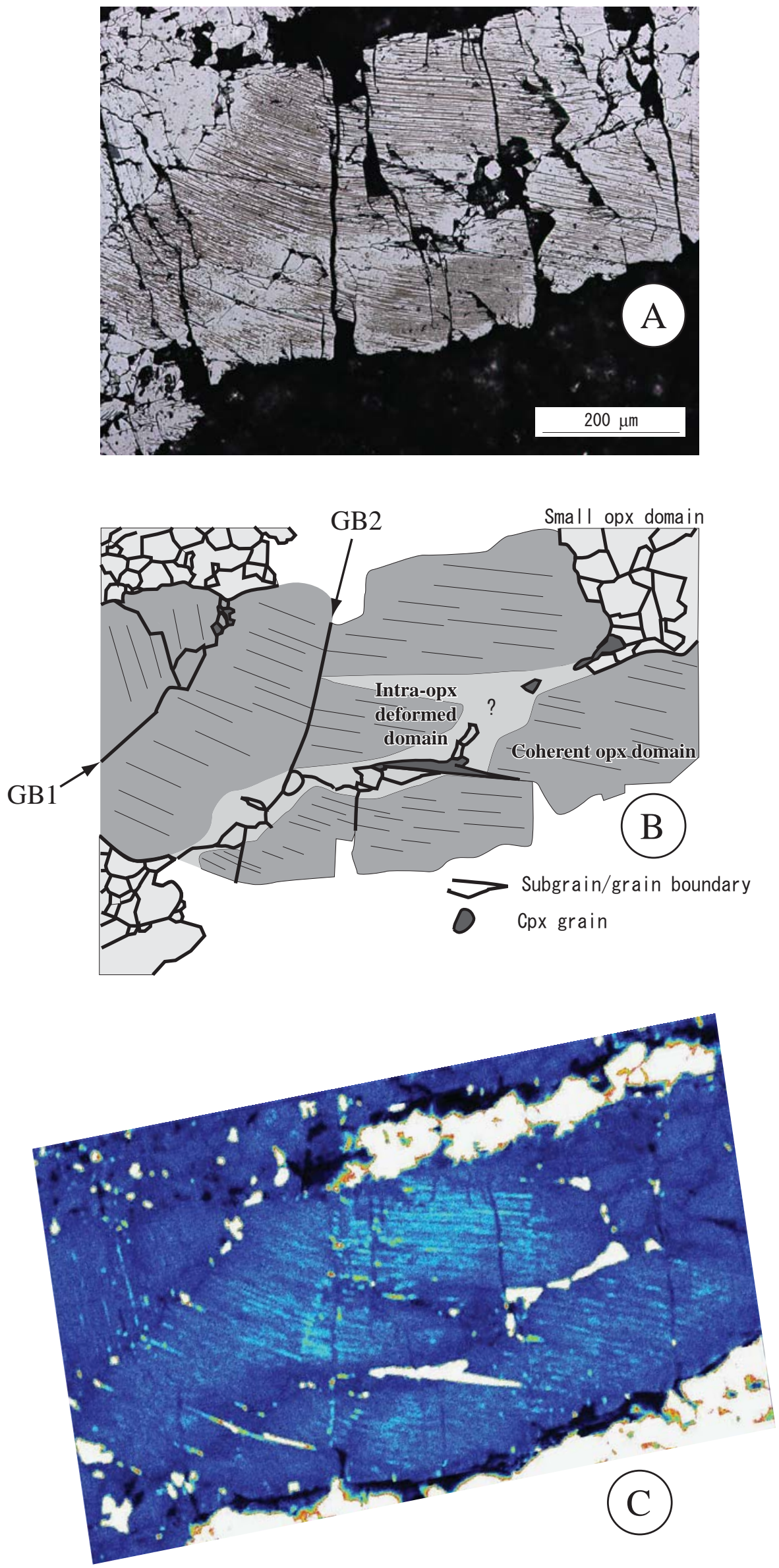

Figure Supplementary material 2 


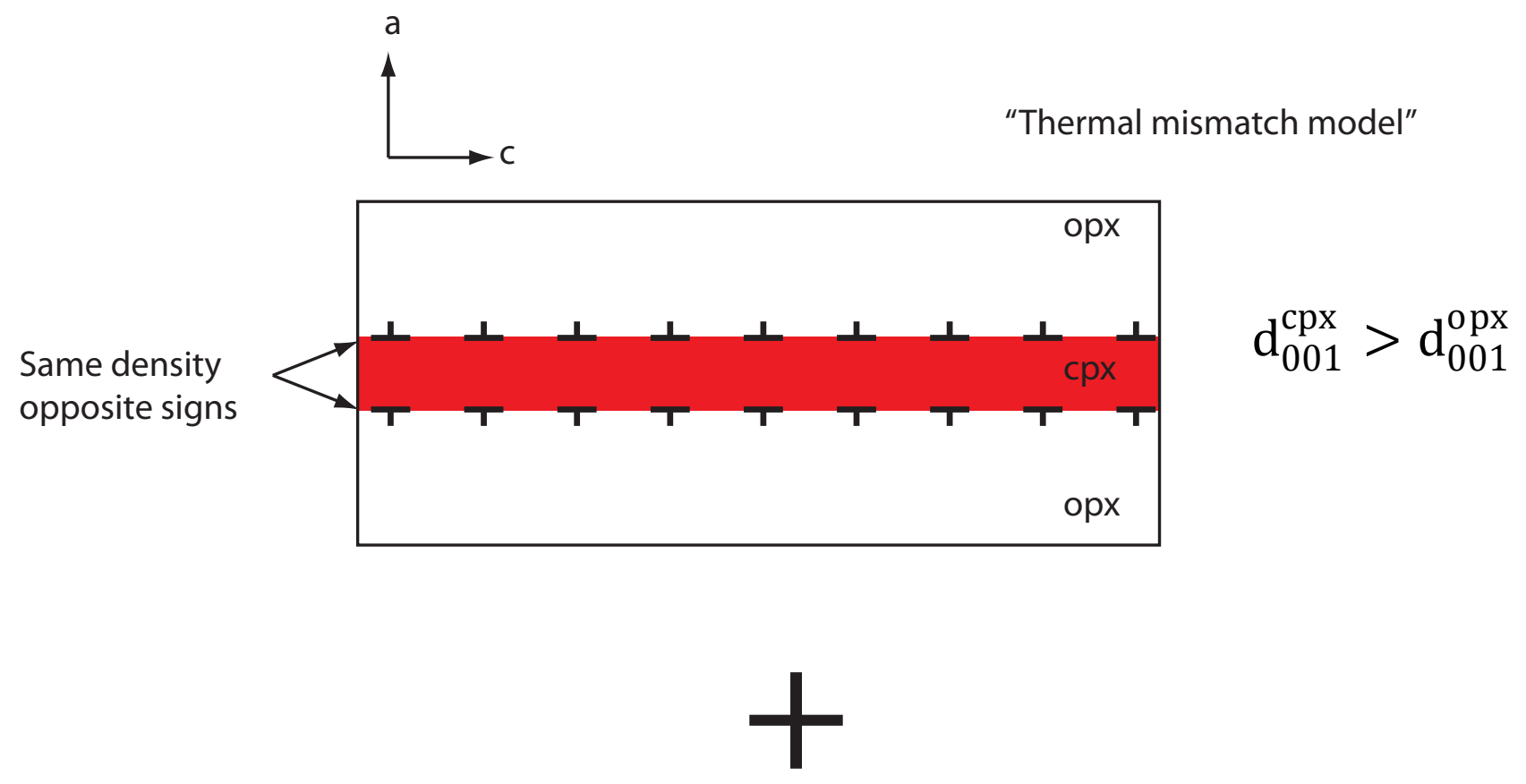

"Flexural slip model"
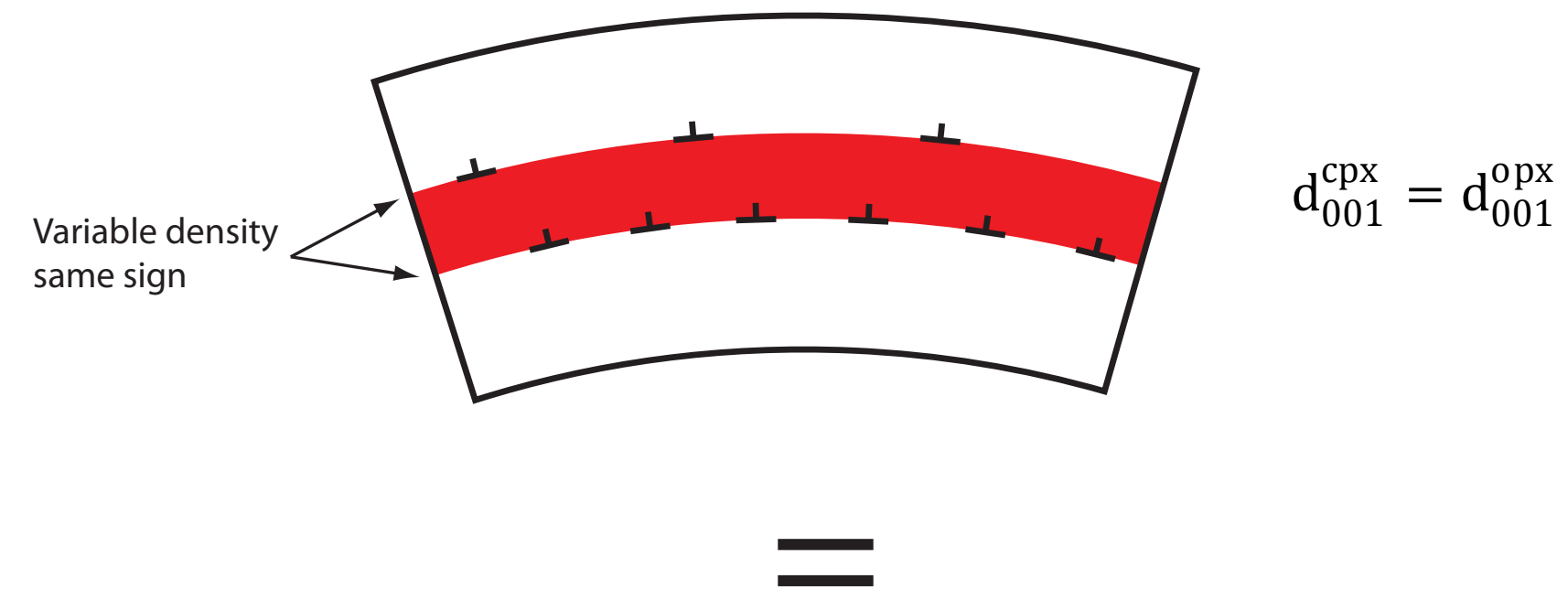

Actual dislocation distribution

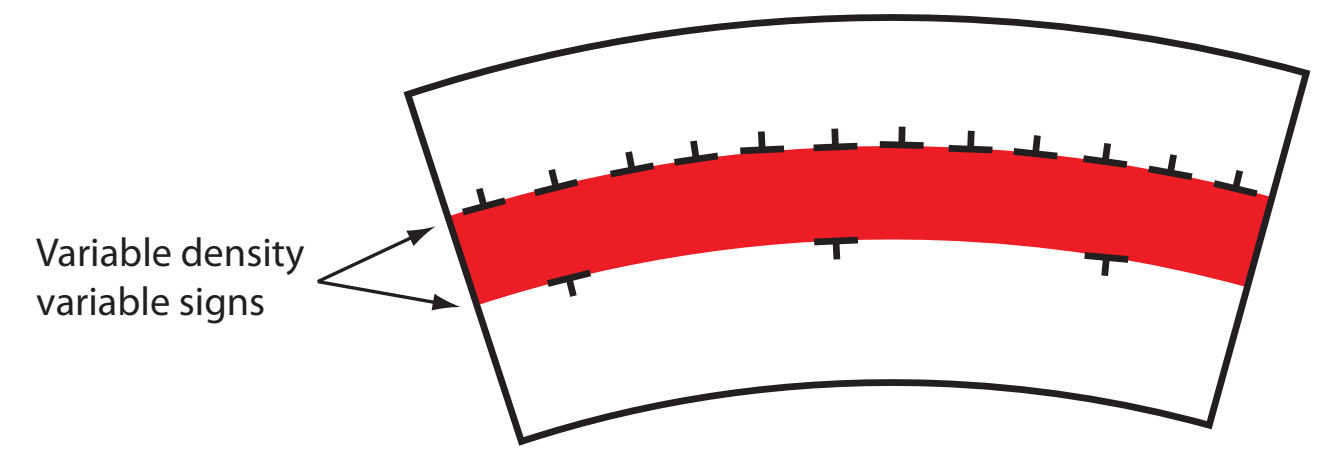

